\title{
Numerical Investigation of Arches in Brick-Masonry Bridges
}

\author{
Yanyang Zhang ${ }^{1}$, Lorenzo Macorini ${ }^{2 *}$, Bassam A Izzuddin ${ }^{3}$
}

${ }^{1}$ Postdoctoral Research Fellow, Key Laboratory of Transportation Tunnel Engineering, Ministry of

Education, Southwest Jiaotong University, Chengdu, Sichuan, China. Formerly, Research

Student, Department of Civil and Environmental Engineering, Imperial College London, South

Kensington Campus, London, UK, Email: y.zhang10@imperial.ac.uk

${ }^{2}$ Senior Lecturer, Department of Civil and Environmental Engineering, Imperial College London,

South Kensington Campus, London, SW7 2AZ, UK, Tel: +44 (0)20 75946040 Email:

1.macorini@imperial.ac.uk

${ }^{3}$ Professor of Computational Structural Mechanics, Department of Civil and Environmental

Engineering, Imperial College London, South Kensington Campus, London, UK Email:

b.izzuddin@imperial.ac.uk

* Corresponding author 


\title{
Numerical Investigation of Arches in Brick-Masonry Bridges
}

\begin{abstract}
A significant number of old masonry bridges are still in use and need to be assessed considering current traffic loading and safety requirements. Masonry bridges are complex heterogeneous systems, where masonry arches represent the main components. Thus a realistic modelling of arches is vital for accurate assessment of masonry bridges. The authors have previously proposed and validated a detailed mesoscale description for masonry arches allowing for the actual masonry bond and the specific arch geometry including the case of skew arches. In this paper, the proposed mesoscale modelling strategy is used in a comprehensive numerical study to investigate the effects of various parameters, including masonry bond and defects in the brickwork, abutment stiffness and movements at the supports, which are usually disregarded in practical assessment of masonry arches and bridges. The results achieved show how these parameters affect the ultimate load capacity, failure mechanisms and initial stiffness of square and skew arches, where the used of detailed 3D mesoscale modelling is critical in providing accurate response predictions under a variety of loading conditions for which reduced models might provide incorrect results.
\end{abstract}

Keywords: masonry; nonlinear analysis; 3D modelling; mesoscale description; domain partitioning approach; square and skew arches.

\section{Introduction}

Masonry arches represent critical components in old masonry bridges, which were built following crude design rules based upon basic structural mechanics principles and empirical evidence (Benvenuto, 1981; Brencich \& Morbiducci, 2007; De Santis \& de Felice, 2014). At present, these structures need to be assessed considering current safety requirements and loading conditions. Past laboratory and in-situ tests (Hendry, Davies, \& Royles, 1985; Pippard, Tranter, \& Chitty, 1936; Pippard \& Ashby, 1939; Pippard \& Chitty, 1941; Royles \& Hendry, 1991; Wang, 2004; Melbourne et al., 2007) showed that the structural response of masonry arches is very complex and characterised by different failure modes. Thanks to the development of computational techniques for nonlinear structural analysis, various numerical strategies for assessing arches in masonry bridges have been proposed in recent past (Nobile \& Bartolomeo, 2015; Sarhosis, et al., 2016). These are based on limit analysis concepts (Cavicchi \& Gambarotta, 2005; Cavicchi \& Gambarotta, 2007; Gilbert, 2007), the finite element method (FEM) (Crisfield, 1984; de Felice, 2009; Milani \& Lourenço, 2012; Milani \& Tralli, 2012; De Santis \& de Felice, 2014), the discrete element method (Lemos, 2007; Sarhosis, Oliveira, Lemos, \& Lourenco, 2014), and discontinuous modelling techniques (Thavalingam, Bicanic, 
Robinson, \& Ponniah, 2001). However, most of previous research focused mainly on the analysis of the ultimate capacity of masonry arches subjected to gravity loading, without providing a deep insight on the response at different loading levels up to collapse, especially in the case of skew arches. Moreover, the effects of defects in the brickwork and potential movements at the supports have yet to be fully explored.

Recently, the authors proposed and validated an advanced modelling strategy for masonry arches (Zhang, Macorini, \& Izzuddin, 2016) which is based upon a nonlinear mesoscale masonry description (Macorini \& Izzuddin, 2011). It allows for the specific masonry bond and geometrical characteristics including the case of skew arches. The accuracy of this mesoscale modelling approach has been confirmed in a number of experimental-numerical comparisons on square spanning arches (arches with no skew or very small degree of skew, McKibbins et al., 2007) and skew arches. It has been shown that the use of the proposed numerical description enables a realistic response prediction up to collapse, accurately predicting the development of damage at different loading levels and the most critical failure mechanisms of multi-ring brick-masonry square and skew arches.

In this paper, this advanced modelling strategy is used in a comprehensive numerical study to investigate the effects of different parameters on the structural behaviour of masonry arches. Multiring arches with segmental circular shape built using the stretcher and the header bond method, and characterised by different rise-to-span ratios, are analysed. In this respect, the geometry of typical arches found in a statistical survey on old masonry bridges (Brencich \& Morbiducci, 2007) is considered. According to this study, 50\% of the brick-masonry bridges within the Italian railway network built between 1830 and 1940 are formed by arches with 0.5 rise-to-span ratio (deep arches). The remaining bridges are shallow arch bridges with a rise-to-span ratio in the range of 0.1-0.4.

To study the influence of defects in the brickwork, the response of defective arches with weak circumferential mortar joints connecting adjacent rings are compared to that of arches with uniform (strong) mortar joints. Previous studies pointed out that "defective" mortar joints in multi-ring arches without headers may facilitate ring separation. In real bridges, imperfection in mortar joints may be caused by mortar wash out or due to the use of poor material which leads, in time, to "ring delamination". Beare (1993) highlighted that ring debonding is the most common defect in multi-ring arches with stretcher bond. Besides, according to Sunley (1990) all existing brick-masonry bridges with insufficient interconnecting headers are defective, whether or not they are weakened by existing cracks or ring separation. To explore the behaviour of masonry arch bridges prone to ring separation, Melbourne and Gilbert (1995) performed physical tests on models of arch bridges, where damp sand was used rather that standard mortar to bond arch rings so as to promote ring separation. The results of this study confirmed that ring separation strongly influences the response up to collapse, reducing the load capacity. Moreover, it was found that ring debonding may occur not only in arches with weak joints connecting adjacent rings, but also in arches with mortar joints of good quality. 
In addition to the above, further numerical simulations are carried out in this paper to study the effects of the abutment stiffness and movements at the supports. In this respect, the failure modes induced by differential vertical settlements and inward and outward horizontal displacements at the abutments are investigated, and the influence of these movements on the arch load capacity is analysed. The paper proceeds with a brief description of the adopted modelling strategy for masonry arches. Focus is then shifted to square and skew arches, where the results of the various numerical investigations are presented and critically discussed. It is important to point out that, according to the adopted numerical strategy (Zhang et al., 2016), 3D nonlinear simulations of large multi-ring arches are carried out using a partitioning approach combined with the masonry mesoscale description. This allows for parallel computation enhancing computational efficiency. On the other hand, when using conventional computational resources (e.g. monolithic simulations) the analysis of large arches with the detailed 3D mesoscale description is impractical, as it requires an excessive computational cost (e.g. it may take several hours to complete a nonlinear simulation, Zhang et al., 2016). In these cases, adequate predictions of the arch ultimate capacity can be obtained through efficient limit analysis.

\section{Modelling strategy for masonry arches}

Masonry arches are modelled using the mesoscale masonry description previously developed at Imperial College (Macorini \& Izzuddin, 2011). It enables an accurate representation of the 3D domain of any brick-masonry arch, as the actual 3D masonry bond is represented using two or more elastic solid elements for each brick and 2D nonlinear interface elements for mortar joints (Figure 1a). In the constitutive model for interface elements, material nonlinearity is taken into account employing a cohesive model. This effectively describes the development damage, cracks and plastic separations. In particular, a multi-surface plasticity criterion is utilised (Figure 1b), where a hyperbolic failure surface $F_{l}$ based on the Coulomb slip criterion determines the boundaries of the elastic domain representing Mode-I and Mode-II fracture:

$$
F_{1}=\tau_{x}^{2}+\tau_{y}^{2}-(C-\sigma \tan \phi)^{2}+\left(C-\sigma_{t} \tan \phi\right)^{2}
$$

where $C$ represents the cohesion, $\phi$ the friction angle and $\sigma_{t}$ the tensile strength for mortar joints or brick-brick interfaces. The second yield function corresponds to a cap model in compression, and it is given by another hyperbolic function:

$$
F_{2}=\tau_{x}^{2}+\tau_{y}^{2}-(D-\sigma \tan \theta)^{2}+\left(D-\sigma_{c} \tan \theta\right)^{2}
$$

where $\sigma_{c}$ is the compressive strength of masonry while $D$ and $\theta$ are material parameters governing the shape of the cap surface. The degradation of the material parameters is modelled using a work-softening plasticity approach. In this way tensile strength $\sigma_{t}$ and friction angle $\phi$ reduce to residual values when the plastic work $W_{c r l}$ approaches Mode-I fracture energy $G_{f l}$. In a similar way cohesion $C$ at the interface reaches its residual value when $W_{c r l}$ converges to the Mode-II fracture 
energy $G_{f I I}$. A non-associated flow rule is employed and a plastic potential $Q_{1}$ similar to function $F_{1}$ (Figure 1b), but with a different friction angle parameter is adopted to model the actual dilatancy. This due to the roughness of the fractured shear surface and can be measured in tests on interfaces.

The main drawback of the adopted mesoscale strategy is the computational cost, which becomes excessive when analysing large arches of realistic masonry bridges. In these cases, as suggested in (Zhang et al., 2016), the mesoscale description is used within the advanced partitioning approach previously developed at Imperial College (Jokhio \& Izzuddin, 2013; Jokhio \& Izzuddin, 2015; Jokhio \& Izzuddin, 2016) which enhances computational efficiency, achieving exceptional computational benefits through parallelisation on High Performance Computing (HPC) systems. As shown in previous studies on masonry structures (Macorini \& Izzuddin, 2013; Zhang et al., 2016), the used of the mesoscale partitioned approach guarantees exactly the same accuracy of the 3D mesoscale description at structural scale.

In (Zhang et al., 2016), the proposed mesoscale partitioned strategy has been validated considering experimental tests on multi-ring square arches subjected to line loads and a multi-ring skew arch subjected to a patch load. Figure 2 shows some results of the numerical-experimental comparisons for the skew arch, where a good agreement between the numerical predictions and the experimental data can be observed both in term of force-displacement curve and failure mode description. A detailed validation of the adopted mesoscale strategy can be found in (Zhang et al., 2016).

\section{Mesoscale analysis of square arches}

The static response of square arches is investigated by simplified mesoscale "strip" models (Zhang et al., 2016) utilising only one set of solid elements along the span for each arch ring. Zhang et al. (2016) pointed out that a detailed modelling of the brick-mortar arrangement along the width of the arch is not critical when analysing square arches subjected to vertical static loads uniformly distributed on a strip along the whole width of the arch. Numerical comparisons between strip and full 3D models allowing for the actual arch geometry and masonry bond showed practically coincident results in term of load-displacement response, where the distributions of stresses and plastic work are uniform along the arch width for different loading levels up to collapse. Thus in the analysis of square arches subjected to line loads, mesoscale strip models generally represent a good compromise between accuracy and computational efficiency. Hereinafter, for convenience, square arches with unit width $(1 \mathrm{~m})$ are considered.

\subsection{Effects of rise-to-span ratio}

The response up to collapse of segmental arches characterised by the most common rise-to-span ratios as found in a number of existing masonry arch bridges (Brencich \& Morbiducci, 2007) are analysed. 
These include eight arches with two or five rings connected by good quality mortar. The main geometrical properties of the arches are reported in Table 1.

The loading arrangement encompasses two initial vertical (dead) loads (DLs) and an additional vertical live load $(L L)$ applied at quarter span and increased up to collapse under displacement control. The two identical dead loads are equal to $22.5 \mathrm{kN} / \mathrm{m}$ for the arches with $3 \mathrm{~m}$ span and to $100 \mathrm{kN} / \mathrm{m}$ for the $8 \mathrm{~m}$ span arches. As in the experimental tests presented in Melbourne et al. (2007), which were considered by the authors for the model validation in Zhang et al. (2016), the dead loads are applied at the quarter and three quarter span representing the weight of the backfill in typical masonry arch bridges. Of course a more realistic representation of the backfill contribution should consider the actual vertical loading distribution due to the backfill weight and the load spreading and restraining effects on the arch deformation provided by the backfill. This it is not considered in the present study, as it would require a detailed representation of the arch-backfill interaction which is outside the scope of this paper and it will be considered in future research.

In the numerical simulations the material properties assumed in (Zhang et al., 2016) for model validation are used. In particular masonry units have been modelled assuming Young's modulus $E_{b}=$ $1.60 \times 10^{4}[\mathrm{MPa}]$ and Poisson's ratio $v=0.15$. Mortar joint interfaces have been represented by using normal and tangential stiffness values of $K_{n}=90\left[\mathrm{~N} / \mathrm{mm}^{3}\right]$ and $K_{t}=40\left[\mathrm{~N} / \mathrm{mm}^{3}\right]$ and the inelastic material parameters for reported in Table 2 , where $C_{0,}, \sigma_{\mathrm{t} 0}, \tan \phi_{0}$ represent cohesion, tensile strength and tangent of friction angle for yield function $F_{1}, G_{f l}$ and $G_{f 2}$ fracture energies for Mode-I and Mode-II fracture, $\tan \psi_{0}$ tangent of friction angle for plastic potential Q1, $\sigma_{\mathrm{c} 0}$ compressive strength of masonry, $G_{\mathrm{c}}$ crushing energy; $D \tan \theta_{0}$ are material parameters determining the shape of the cap in compression $F_{2}$, Figure $1 \mathrm{~b}$ (Macorini \& Izzuddin, 2011).

Similar results have been found for arches with different span length. The deformed shapes and the plastic work $W_{c r l}$ contours at the end of the numerical simulations are shown in Figure 3. It can be seen that in the case of deep arches and arches with 1:4 rise-to-span ratio the failure mechanism is a typical "hinge mechanism", which is governed by the development of four radial cracks at the opposite haunches and at about the quarter and the three quarter span. Conversely in the case of the two arches with 1:8 and 1:10 rise-to-span ratio, radial cracks are combined with ring separation, which takes place at the arch haunch close to the live load. This is mainly caused by the shear forces in the arch which generally increase when the rise-to-span ratio reduces, becoming relatively large for very shallow arches (Dym \& Williams, 2011).

Figure 4 displays the load-displacement curves at quarter span for the arches with $3 \mathrm{~m}$ and $8 \mathrm{~m}$ span. A significant change in the response for different rise-to-span ratio values can be observed. The deep arch is characterised by the lowest loading capacity but a notable ductility; after reaching the maximum load the displacements significantly increase while the load remains almost constant. The ultimate load rises for arches with low rise-to-span ratio, but the response up to the maximum load becomes less smooth especially for the very shallow arch (1:10 rise-to-span ratio). In this case while 
three radial cracks around the two springings and at about the quarter span develop gradually, ring separation occurs suddenly producing a rapid release of elastic energy and causing an abrupt softening in the load-displacement curve. After a short almost flat branch, where the displacement increases while the live load remains constant, the load-displacement curve rises again up the ultimate load. This is reached when the fourth radial crack forms at about three quarter span.

\subsection{Effects of brickwork defects}

Four defective arches prone to ring separation have been investigated. These are characterised by geometrical features identical to those of the Arch 1, Arch 2, Arch 3 and Arch 4 analysed in the previous section, but are constructed with weak circumferential mortar joints. In this respect, very small cohesion and tensile strength values, $C_{0}=0.004 \mathrm{~N} / \mathrm{mm}^{2}$ and $\sigma_{t 0}=0.002 \mathrm{~N} / \mathrm{mm}^{2}$, are employed for the interface elements representing the joints which connect the two rings. These include reduced cohesion, tensile strength and friction angle values. In Figure 5, the deformed shapes and the plastic work contours at the last step of the numerical simulations are displayed, whereas in Figure 6 the load-displacement curves are shown. In all the cases ring separation characterises the response at collapse and the failure modes. Comparing the curves plotted in Figures 4a and 6, it can be seen that the poor connection between the two rings significantly influences the load-displacement response of the four arches. Ring separation starts at very low load levels, and its development is gradual leading to progressive stiffness degradation up to the ultimate load, but not to a sudden force reduction as for the very shallow arches with good quality mortar (e.g. Arch 3 and 4). More than 50\% strength reduction can be observed for all the analysed arches. This highlights the critical role played by the connections between adjacent rings and the importance of a correct evaluation of the mechanical characteristics of the mortar joint for an accurate response prediction of existing masonry arches.

\subsection{Effects of loading position}

Multi-ring arches with $3 \mathrm{~m}$ span are analysed here to study the influence of the loading position on the response up to collapse. Particular attention is given to the ultimate capacity and the type of failure mechanism. In the numerical simulations, two dead loads $(22.5 \mathrm{kN} / \mathrm{m})$ were applied at quarter and three quarter span, while a live load was placed at four different positions: close to the left springing (Case 1), at 1/8 span (Case 2), at quarter span (Case 3) and at mid-span (Case 4), and then increased up to collapse.

Deformed shapes and the plastic work contours at collapse for the arch with 1:4 rise-to-span ratio (Arch 2) are shown in Figure 7. Different failure mechanisms can be clearly noticed. In Case 1 the load near the left support induces a local failure mode; this is due to shear sliding at the radial bed joint close to where the load is applied. In Case 3 only radial cracks form (high mechanism), while in Case 2 and Case 4 radial cracks are accompanied by ring separation. This develops at the left haunch 
close to the live load in Case 3, and symmetrically at both haunches when the live load is applied at mid-span.

In Figure 8a, the displacements at the live load position for the four different cases are plotted against the live load. It can be seen how the response characteristics including the ultimate load, the initial stiffness and the arch ductility strongly depend upon the location of the live load. When the load is applied near the support, the load capacity of the arch is influenced by its ability to resist shear forces. These may cause plastic shear sliding at radial bed joints as in Case 1, or ring separation associated with local failure as in Case 2. In both cases shear failure prevents an adequate redistribution of internal forces limiting the arch ductility. On the other hand the response of Arch 2 under a live load applied at quarter span is very ductile, being governed by the formation of radial cracks (Figure 7c) leading to a four-hinge mechanism without ring separation. Figure $8 \mathrm{~b}$ presents the ultimate load values for arches with different rise-to-span ratios (e.g. Arch 1 to 4) loaded at different positions. The results show that the condition with loads close to the supports is the most critical for very shallow arches, while the lowest load capacity for the deep arch and the arch with intermediate $1: 4$ rise-to-span ratio is achieved when the live load is applied at quarter span.

\subsection{Effects of abutment stiffness}

In the previous numerical simulations, square arches have been modelled assuming that the supports at the springings are perfectly rigid. In this section, the effects of potential deformations at the abutments are investigated. These may develop in real arch bridges under the forces transferred by the masonry arch to the foundations. To analyse the effects of the abutment stiffness, elastic interface elements are used to connect the arch springings to fixed supports so as to represent elastic abutments. In particular, the $3 \mathrm{~m}$ span arches presented previously have been analysed employing the five pairs of elastic normal and tangent stiffness values reported in Table 3. The numerical results confirmed that the failure mechanism does not change by varying the stiffness at the lateral supports, and in all the cases arch failure is reached when a hinge mechanism with four radial cracks forms.

The load-displacement curves showing the response of Arch 2 are plotted in Figure 9a. The variation of the ultimate load and the secant stiffness of the arch calculated at $40 \%$ of the ultimate load (Zhang et al., 2016) with the abutment stiffness are displayed in Figures 10b,c. Ultimate load and secant stiffness do not change significantly for large abutment stiffness values, but they both notably reduce for a normal and tangential stiffness at the abutments of $1 \mathrm{~N} / \mathrm{mm}^{3}$. In this case, a reduction of $46 \%$ for the ultimate load and $60 \%$ for the secant stiffness compared to the arch with perfectly rigid supports can be observed. As shown in Figure 10, when arches with different rise-to-span ratios are analysed, different variations of stiffness and strength can be noticed. In particular, for very shallow arches (e.g. 1:10 and 1:8 rise-to-span ratios) only a marginal reduction of the load capacity can be observed, but the stiffness variation is remarkable. 


\subsection{Effects of movement at abutments}

Movement at the abutments and piers resulting from the instability of the foundations is one of the most common causes of deterioration for masonry arch bridges. In general, the performance of masonry arch barrels, which are the most critical structural components in masonry bridges, is highly affected by differential settlements (McKibbins et al. 2006). Support movements may occur during the bridge construction or may be caused by extreme events (e.g. earthquakes) or due to a change in the soil conditions below the foundations. Moreover if the bridge is built on waterways, water flow may induce scour at the footings of piers and abutments, often leading to the collapse of the bridge. In practical assessment of masonry arch bridges, the formation of three hinges caused by vertical or horizontal differential movements at the supports represents a failure mechanism, and indicates that the arch should be immediately repaired (McKibbins et al. 2006).

In this section, the possible consequences and effects of different types of support movements are investigated. To this end, the square arches with $3 \mathrm{~m}$ span considered before (Arch 1, Arch 2, Arch 3, Arch 4) are analysed considering the settlement modes shown in Figure 11. Afterwards, different levels of support displacements are applied before increasing the live load at quarter span up to collapse. Moreover, the influence of defects in masonry is investigated comparing the response of arches with good quality brickwork (strong joints) against that of arches with weak mortar joints connecting the two rings (weak joints).

Figure 12 displays the deformed shapes for Arch 2 subjected to the three settlement modes and the plastic work $W_{\text {crl }}$ contour for the different cases. All these figures refer to the last step of the numerical simulations at the failure of the arch. The failure mode depends not only on the specific type of settlement but also on the brickwork characteristics and does not always involve the formation of three main radial cracks (hinges). In the case of horizontal spread of support and horizontal inward movement, three radial cracks develop in the arch with good quality joints, but in the arch with weak mortar joints radial cracks occur with ring separation, which extends from the arch crown to the left support moving laterally. On the other hand, when vertical differential settlements are applied only two main radial cracks form at the springings of the arch.

The imposed displacements at the left support are plotted against the associated reaction forces in Figure 13. It can be seen that when the failure mechanism due to a specific settlement mode develops, the associated reaction force decreases showing a post-peak softening response which is steeper for the arch with strong joints. Moreover it can be noticed that the support displacement required to form a mechanism is notably lower for arches with good quality mortar joints especially in the case of horizontal inward displacements.

\subsubsection{Horizontal spread of support}

Numerical simulations were carried out to investigate the response of the $3 \mathrm{~m}$ span arches subjected to different levels of prescribed horizontal displacements followed by the application of a line load at 
quarter span. In particular, static time-history analyses were performed considering two phases, where two loading conditions were applied in sequence. In the initial phase, a specific horizontal outward displacement $\delta_{\text {ss }}$ was exerted at the left springing of the arch incrementally; afterwards the line load was increased up to collapse. Six $\delta_{\text {ss }}$ values were considered within the interval $1 \mathrm{~mm} \leq \delta_{\text {ss }} \leq 6 \mathrm{~mm}$, where the upper limit is higher than the horizontal spread of support at which a mechanism starts to develop. The numerical responses were calculated under force control, thus the nonlinear analyses terminated when the maximum loads were reached without describing the post-peak behaviour.

Figures 14a,b display the numerical curves for Arch 2 with strong and weak mortar joints, where the line load is plotted against the vertical displacements at quarter span. It can be seen that the load capacity of the arch with good quality mortar joints significantly decreases when $\delta_{\mathrm{ss}}$ rises, and about $60 \%$ reduction is calculated for $6 \mathrm{~mm}$ horizontal support displacement. On the other hand, in the case of defective brickwork (weak joints), the reduction in load capacity is less pronounced reaching about $18 \%$ for $6 \mathrm{~mm}$ horizontal displacement. This is due to the characteristics of the response under horizontal spread of support (see Figure 13a,b), where the arch with weak joints shows a more ductile behaviour.

Figure 15 shows some results for the arch with strong joint and subject to $1 \mathrm{~mm}$ and $6 \mathrm{~mm}$ spread of support. In the two figures the deformed shapes and the contours of the plastic work $W_{\text {crl }}$ after the application of the two support movements and at collapse are displayed. It can be observed that the lower prescribed displacement induces the formation of two cracks at the opposite springings, while at collapse a third crack forms close to where the line load is applied. When a higher displacement is exerted, even though the mechanism associated with the support prescribed displacement forms, the arch can still carry additional live load and the collapse is attained only when a more crack develops below the load.

The influence of the horizontal spread of abutment on the load capacity of masonry arches with strong mortar joints and different rise-to-span ratios is shown in Figure 16. The ratio between the ultimate load achieved after the application of different horizontal outward displacements at the left support and the ultimate load calculated with fixed supports for the arches Arch 1, Arch 2, Arch 3 and Arch 4 is plotted against the prescribed displacement values. A similar variation of the ultimate capacity can be observed for the first three arches, with a maximum reduction of $46 \%$ for the arch with 1:8 rise-to-span ratio under a $5 \mathrm{~mm}$ horizontal support displacement.

\subsubsection{Vertical settlement of support}

As for the case of horizontal spread of support, the influence of differential vertical settlements on the arch load capacity was investigated performing time-history analyses, where different levels of vertical displacements $\delta_{\mathrm{sv}}$ were imposed on the left abutment before loading the arch at the quarter span up to collapse. Six $\delta_{\mathrm{sv}}$ values were considered within the interval $1 \mathrm{~mm} \leq \delta_{\mathrm{sv}} \leq 6 \mathrm{~mm}$, where the upper limit is about the vertical settlement at which a mechanism starts to develop for Arch 2 with 
strong circumferential mortar joints. Also in this case the numerical responses were calculated under force control, thus the nonlinear analyses terminated when the maximum loads were reached without representing the post-peak behaviour. Figures 17a,b show the load-displacement curves for Arch 2 with strong and weak mortar joints. Examining the results, it can be observed that a vertical support movement does not significantly influence the loading capacity for arches with strong or weak mortar joints. In this case, the considered prescribed displacements are not sufficiently large to notably reduce the load bearing capacity of the arch, especially in the case weak mortar joints, where the maximum vertical settlement is smaller than the displacement level at which a mechanism starts to develop (see Figures 13b). This is confirmed also by Figure 18, where the deformed shapes and the contours of the plastic work $W_{\text {crl }}$ for the smallest and the largest vertical settlements are displayed. The figures show that the support displacement does not influence the collapse mechanism, which corresponds to that of the arch with fixed supports showing four radial cracks at the two springings and at the quarter and three quarter span.

Finally, by investigating the response of arches with different rise-to-span ratios, it has been found that the support vertical movement may induce a strain/stress state in the arch which mitigates the effects of the live load, thus increasing the load capacity as for the arch with 1:8 rise-to-span ratio (Arch 3, Figure 19). Evidently the settlement level should be lower than the limit leading to a mechanism.

\subsubsection{Horizontal inward support displacement}

Similar numerical simulations have been carried out to study the effects of horizontal inward movements at the left support. As before, six horizontal inward displacements values $\delta_{\text {im }}$ were considered within the interval $1 \mathrm{~mm} \leq \delta_{\mathrm{im}} \leq 6 \mathrm{~mm}$, where the upper limit is significantly higher than the horizontal inward movement leading to a mechanism for Arch 2 with strong mortar joints, but lower than the same displacement limit for Arch 2 with weak mortar joints (see Figure 13). The loaddisplacement curves in Figure 20 confirm the significant influence of the horizontal inward movement on the arch response. This is critical not only for the arch with strong mortar, where a notable maximum reduction of $46 \%$ have been calculated, but also for the arch with weak circumferential

joints. Moreover it can be observed than the prescribed support displacements give rise to a strain/stress state which opposes the live load which, for relatively small inward movements, may lead to an increment in the load capacity (see curves $\delta_{\text {im }}=1 \mathrm{~mm}$ in Figure 20b).

Concerning the failure mechanisms due to the line load at quarter span applied after the horizontal inward support movement, Figure 21a shows that, in the case of relatively small support displacements, the failure mode corresponds to that of the arch with fixed supports. Conversely, Figure $21 \mathrm{~b}$ highlights that, by increasing the support movement, a different crack pattern forms in the arch. This is similar to that shown in Figure 12c and due to inward support displacements alone, but with a more diffuse cracking at the crown. 
Finally the influence of the horizontal inward support movements on the load capacities of arches with different rise-to-span ratios is shown in Figure 22. It can be seen that the effects of support movement is more critical for shallow arches with 1:8 and 1:10 rise-to-span ratios (e.g. Arch 3 and 4). However in these cases, convergence problems allowed only an approximate estimate of the ultimate load for $5 \mathrm{~mm}$ inward displacement. Thus the calculated $70 \%$ and $83 \%$ reductions in loading capacity should be considered as conservative predictions.

\subsubsection{Modelling considerations}

A parametric study has been conducted to identify the most critical material properties which determine the qualitative response under the combinations of the prescribed support displacements and the live loads considered before. Not surprisingly, it has been found that the fracture energy values (especially Mode-I fracture energy $G_{f l}$ ) strongly affect the numerical predictions. In particular, using unrealistically large fracture energy values (e.g. two orders of magnitude larger than the values in Table 2), the response prediction under the live load seems to be almost independent from the level of support displacement, as well as the ultimate load capacity. This is shown in Figure 23, where the live load is plotted against the vertical displacement at quarter span for the three types of support displacement. The results obtained confirm that the use of large fracture energy values, which disregard the actual quasi-brittle nature of the mortar joints and the fracture in the masonry units, usually transfers the numerical response towards the elastic-plastic limit, where the solution does not depend upon potential support movements.

\section{Mesoscale analysis of skew arches}

In (Zhang et al., 2016), it has been shown that for an accurate analysis of skew masonry arches a full 3D mesoscale description accounting for the actual 3D masonry bond should be considered. In this case the use of a more efficient strip model may lead to unrealistic results.

In the following, the detailed 3D mesoscale strategy for skew arches presented in (Zhang et al., 2016) is adopted to investigate the response of brick-masonry skew arches considering the effects of (i) rise to span ratio, (ii) masonry bond and defects in the brickwork, (iii) abutment stiffness and (iv) support movements. The two-ring skew arch with header bond investigated in (Zhang et al., 2016) (Figure 2) is considered here as the reference model. Thus all the analysed arches are characterised by a $3 \mathrm{~m}$ direct span, $670 \mathrm{~mm}$ width, $215 \mathrm{~mm}$ thickness and $45^{\circ}$ skew angle.

\subsection{Effects of rise-to-span ratio}

The effects of the skew arch geometry have been analysed by comparing the numerical responses of three arches with different rise-to-span ratios. The main geometrical properties are reported in Table 4, while Figure 24 shows the three FE mesoscale meshes. The material properties considered in (Zhang et al., 2016) for the validation of the proposed mesoscale description for skew arches are used in the 
numerical simulations. Thus masonry units have been modelled assuming Young's modulus $\mathrm{E}_{\mathrm{b}}=$ $1.60 \times 10^{4}[\mathrm{MPa}]$ and Poisson's ratio $v=0.15$. Mortar joint interfaces have been represented by using normal and tangential stiffness values of $K_{n}=36\left[\mathrm{~N} / \mathrm{mm}^{3}\right]$ and $K_{t}=20\left[\mathrm{~N} / \mathrm{mm}^{3}\right]$ and the inelastic material parameters for mortar joints reported in Table 5 . In the numerical simulations, a line load was applied near the three quarter span perpendicularly to the oblique span. Figure 25 shows the deformed shapes and the plastic work $W_{\text {crl }}$ contours at the end of the numerical simulations. In all the cases failure occurred because of the development of five main cracks along the mortar bed joints forming the typical 3D mechanism with five "hinges".

In Figure 26 the numerical load-displacement curves measured at quarter and three quarter span are plotted. The deep arch features the highest load capacity but a limited ductility, as it shows a softening behaviour just after reaching the maximum load. The arch Skew 2 is characterised by the lowest load capacity but a notable ductility. Finally, the arch with a 1:8 rise-to-span ratio shows an intermediate response. In this case the analysis stopped because of convergence problems probably before reaching the maximum load.

\subsection{Effects of masonry bond and brickwork defects}

The three arches with different rise-to-span ratios presented in the previous section, has been analysed considering different masonry bonds and defective brickwork. In particular, the response of arches built with the stretcher or the header method (Figure 27) to connect the adjacent rings have been compared. Moreover the effects of defective mortar joints at the interface between the two brickwork rings have been taken into account. In this case, very small tensile strength and cohesion values for the nonlinear interface elements representing the circumferential mortar joints, $C_{0}=0.004 \mathrm{~N} / \mathrm{mm}^{2}$ and $\sigma_{t 0}=0.002 \mathrm{~N} / \mathrm{mm}^{2}$, have been employed.

Figure 28 displays the load-displacement curves for the arches with 1:4 rise-to-span ratio (Skew2) and the deformed shapes obtained from the different models and the corresponding plastic work contours are illustrated in Figure 29. Ring separation occurs only in the arch built according to the stretcher method and with defective circumferential mortar joints (weak joints). This arch is also characterised by the lowest load capacity, but it shows a significant ductility as depicted in Figure 28 . All the other numerical curves are very close, being characterised by practically identical initial stiffness, ultimate load and alike post-peak response. This is reflected into very similar failure modes with cracks along the mortar bed joints without ring separation.

Besides, the influence of defective brickwork on the behaviour of skew arches with different rise-tospan ratio has been investigated. Numerical analyses have been carried for the arches Skew 1, Skew 2 and Skew 3 with stretcher bond. In all the cases, weak circumferential mortar joints have been considered. Figure 30 displays the load-displacement curves. As for the arches with header bond and strong joints (Figure 28), the deep arch is characterised by the highest load capacity, the arch Skew 2 
by the lowest peak load, while the arch Skew 3 shows an intermediate behaviour. However when compared against the numerical responses in Figure 30, all the curves for arches with stretcher bond and defective brickwork show higher ductility. This is associated with the development of ring separation which is coupled with cracks in the mortar bed joints.

The influence of mortar defects is summarised in Figure 31, where the ultimate loads and the secant stiffness values obtained in the analysis of arches with weak and strong joints are compared. It has been found that defective brickwork leading to ring separation significantly reduces both initial stiffness and load capacity, where the maximum reduction of stiffness $(60 \%)$ and ultimate load (68\%) have been calculated for the arch with 1:8 rise-to-span ratio.

\subsection{Effects of the abutment stiffness}

The influence of the abutment stiffness on the response of square arches was examined previously. The effects of potential deformations at the abutments on the response of an arch with $45^{\circ}$ skew angle are investigated here. Also in this case, elastic interface elements are used to connect the arch springings to fixed supports so as to represent elastic abutments. Again, the reference skew arch (e.g. arch Skew 2 with header bond) is analysed considering the four pairs of elastic normal and tangent stiffness values reported in Table 3 . As for the square arches, the failure mechanism does not change by varying the stiffness at the lateral supports, and in all the cases arch failure is reached when a 3D hinge mechanism with five main cracks forms.

The load-displacement curves showing the response of the arch Skew 2 with header bond are plotted in Figure 32a, where the displacement was measured at the centre line of the arch barrel at three quarter span. The variation of the ultimate load and the secant stiffness of the arch with the abutment stiffness are displayed in Figures 32b,c. As for the square arches, only the case with the lowest support stiffness $\left(K_{\mathrm{ab}}=1 \mathrm{~N} / \mathrm{mm}^{3}\right)$ shows a significant change in the response, where an ultimate load (Figure 32b) and stiffness (Figure 32c) reduction can be observed. Moreover when compared to the responses of the arches with fixed supports or higher abutment stiffness, the skew arch with $K_{\mathrm{ab}}=$ $1 \mathrm{~N} / \mathrm{mm}^{3}$ shows a more ductile behaviour with no softening.

\subsection{Effects of abutment movement}

The skew arch collapse mechanisms due to support movements have been investigated considering the response of the reference arch (arch Skew 2 with header bond) subject to the three support displacement modes considered shown in Figure 11. The imposed displacements at the left support are plotted against the associated reaction forces in Figure 33. When the failure mechanisms due to horizontal support displacements develop, the associated reaction forces decrease showing a postpeak softening response. Conversely, in the case of differential vertical support movements, the reaction force remains almost constant for relative large displacement values. The three failure modes 
are associated with the formation of cracks close to the two springings but not at the crown as in the case of square arches.

\section{Conclusions}

The response up to collapse of square and skew brick-masonry arches has been investigated using the validated mesoscale strategy described in (Zhang et al., 2016). The effects of (i) rise-to-span ratio, (ii) loading position, (iii) masonry bond and defects in the brickwork, (iv) abutment stiffness and (iv) support movements have been considered in the numerical study.

In the case of square arches, it has been found that the rise-to-span ratio significantly influences the arch response and failure mode; similar results have been obtained for arches with different span lengths. Deep arches or arches with intermediate rise-to-span ratio generally show a typical four hinge mechanisms, where cracks form in the mortar bed joints. On the other hand, shallow arches may fail by a combination of radial cracks and ring separation, where the latter usually develops abruptly, leading to a sudden realise of elastic energy. Moreover, the arch failure mode strongly depends upon the load position, as line loads close to the springing may induce a brittle collapse, also for arches with high rise-to-span ratio. This may occur because of ring reparation at the arch haunch close to the load, or shear sliding at a radial mortar joint. In the case of multi-ring square arches built according to the stretcher method and with weak circumferential mortar joints, the response is governed by ring separation, which develops gradually causing a progressive stiffness reduction but leading to a more ductile behaviour.

The numerical study on the effects of support stiffness has shown that the abutment deformability may significantly reduce the arch stiffness and the load capacity, but it seems that it does not modify the failure mode characteristics. Finally, the numerical simulations on the effects of abutment movements revealed that brick-masonry arches can support live loads also after the formation of a mechanism due to differential support movements. This additional load bearing capacity depends on the level of abutment displacement. Moreover, it has been shown that the accuracy of these predictions is associated with the ability of the numerical description in representing the quasi-brittle nature of masonry. In fact, the use of a material model which disregards de-cohesion and potential friction reduction (e.g. an elastic-plastic approximation with high fracture energy values) generally leads to unrealistic response predictions, where the arch capacity is insensitive to potential abutment movements.

As opposed to the analyses on square arches which were conducted using efficient strip mesoscale models, full 3D mesoscale descriptions have been adopted in the numerical studies for skew arches. In has been found that arches with different rise-to-span ratio are characterised by a different response, where the deep arch shows the highest load capacity, but the same failure mode with five cracks in the mortar bed joints. On the other hand, arches built according to the stretcher 
method, and made up of detective brickwork with weak circumferential mortar bed joints, may also experience ring reparation. As for square arches, this reduces the initial stiffness but improves arch ductility. The response up to collapse of skew arches subject to abutment movements has been also analysed. It has been found that the failure modes under differential horizontal and vertical support displacements are characterised by the development of cracks at the two springing regions but not at the crown. In the numerical simulations, the use of detailed mesoscale descriptions representing the actual masonry bond has been critical, as it allowed for the first time shedding significant light on salient response characteristics of masonry arches, including skew arches, under a variety of loading conditions for which reduced models might provide an incorrect picture.

Future research will consider the effects of the interaction between masonry arch and backfill, which determines the load capacity of masonry bridges (Reccia et al., 2014) and masonry vaulted structures (Milani et al., 2014).

\section{Acknowledgement}

The authors acknowledge the High Performance Computing (HPC) Services at Imperial College London for providing and supporting the required computing facilities.

\section{References}

Beare, M. (1993). Bridges: repairing old and new. Construction repair, 7, 6-8.

Benvenuto, E. (1981). La scienza delle costruzioni e il suo sviluppo storico, Firenze, Italy: Sansoni.

Brencich, A., \& Morbiducci, R. (2007). Masonry arches: historical rules and modern mechanics. International Journal of Architectural Heritage, 1, 165-89.

Cavicchi, A., \& Gambarotta., L. (2005). Collapse analysis of masonry bridges taking into account arch-fill interaction. Engineering Structures, 27(4), 605-15.

Cavicchi, A., \& Gambarotta, L. (2007). Lower bound limit analysis of masonry bridges including arch-fill interaction. Engineering Structures, 29(11), 3002-14.

Crisfield, M. A. (1984). A finite element computer program for the analysis of masonry arches, Laboratory Report 1115.

de Felice, G. (2009). Assessment of the load-carrying capacity of multi-span masonry arch bridges using fibre beam elements. Engineering Structures, 31(8), 1634-47.

De Santis, S., \& de Felice, G. (2014). Overview of railway masonry bridges with a safety factor estimate. International Journal of Architectural Heritage, 8, 452-74.

De Santis, S., de Felice, G. (2014). A fibre beam-based approach for the evaluation of the seismic capacity of masonry arches. Earthquake Engineering and Structural Dynamics, 43(11), 1661-81.

Dym, C. L., \& Williams, H. E. (2011). Stress and displacement estimates for arches. Journal of Structural Engineering ASCE, 137, 49-58.

Gilbert, M. (2007). Limit analysis applied to masonry arch bridges: state-of-the-art and recent developments, Proc. $5^{\text {th }}$ International Conference on Arch Bridges, Madeira, Portugal,13-28.

Hendry, A. W., Davies. S .R., \& Royles, R. (1985). Test on stone masonry arch at Bridgemill Girvan, Contractor `Report 7, Transport and Road Research Laboratory, UK.

Jokhio, G. A., \& Izzuddin, B. A. (2013). Parallelisation of nonlinear structural analysis using dual partition super elements. Advances in Engineering Software, 60, 81-88. 
Jokhio, G. A., \& Izzuddin, B. A. (2015). A dual super-element domain decomposition approach for parallel nonlinear finite element analysis. International Journal for Computational Methods in Engineering Science and Mechanics, 16, 188-212.

Jokhio, G. A., \& Izzuddin, B. A. (2016). Mixed-Dimensional Coupling for Parallel Partitioned Nonlinear Finite-Element Analysis. Journal of Computing in Civil Engineering, 10.1061/(ASCE)CP.1943-5487.0000633, 04016062.

Lemos, J. V. (2007). Discrete Element Modeling of Masonry Structures. International Journal of Architectural Heritage, 1, 190-213.

Macorini, L., \& Izzuddin, B.A. (2011). A non-linear interface element for 3D mesoscale analysis of brick-masonry structures. International Journal for Numerical Methods in Engineering, 85, 1584-608.

Macorini, L., \& Izzuddin, B.A. (2013). Nonlinear analysis of masonry structures using mesoscale partitioned modelling. Advances in Engineering Software, 60, 58-69.

McKibbins, L.D., Melbourne, C., Sawar, N., \& Sicilia Gaillard, C. (2006). Masonry arch bridges: condition appraisal and remedial treatment, London: CIRIA.

Melbourne, C., \& Gilbert, M. (1995). The behaviour of multiring brickwork arch bridges. The Structural Engineer, 73(3), 39-47.

Melbourne, C., Wang, J., Tomor, A., Holm, G., Smith, M., Bengtsson, P.E., Bien, J., Kaminski, T., Rawa, P., Casas, J.R., Roca, P., \& Molins, C. (2007). Masonry Arch Bridges Background document D4.7, Deliverable D4.7.

Milani, G., \& Lourenço, P. B. (2012). 3D non-linear behavior of masonry arch bridges. Computer \& Structures, 110-111, 133-50.

Milani, G., \& Tralli, A. (2012). A simple meso-macro model based on SQP for the non-linear analysis of masonry double curvature structures. International Journal of Solids and Structures, 49, 80834.

Milani, G., Simoni M., \& Tralli A. (2014). Advanced numerical models for the analysis of masonry cross vaults: A case-study in Italy. Engineering Structures, 76, 339-358.

Nobile, L., \& Bartolomeo, V. (2015). Structural analysis of Historical Masonry Arches: state-of-theart and recent developments. Journal of Mathematical Models and Methods in Applied Sciences, 9, 338-344.

Pippard, A.J.S., Tranter, E., \& Chitty, L. (1936). The mechanics of the voussoir arch. Journal of the ICE, 4, 281-306.

Pippard, A.J.S., \& Ashby, R.J. (1939). An experimental study of the voussoir arch. Journal of the ICE, 10, 383-404.

Pippard, A.J.S., \& Chitty, L. (1941). Repeated load tests on a voussoir arch, Journal of the ICE, 17, 79-86.

Reccia, E., Milani, G., Cecchi A., \& Tralli, A. (2014). Full 3D homogenization approach to investigate the behaviour of masonry arch bridges: The Venice trans-lagoon railway bridge. Construction \& Building Materials, 66, 567-586.

Royles, R., \& Hendry A. W. (1991). Model tests on masonry arches, Proceedings of the ICE, 91, 299321.

Sarhosis, V., Oliveira, D.V., Lemos, J.V., \& Lourenco P.B. (2014). The effect of skew angle on the mechanical behaviour of masonry arches. Mechanics Research Communications, 61, 53-59.

Sarhosis, V., De Santis, S., \& de Felice, G. (2016) A review of experimental investigations and assessment methods for masonry arch bridges. Structure and Infrastructure Engineering, 12:11, 1439-1464.

Sunley, V.K. (1990). In: Sowden AM, editor. The maintenance of brick and stone masonry structures. Taylor \& Francis, 62-80.

Thavalingam, A., Bicanic, N., Robinson, J.I., \& Ponniah, D.A. (2001). Computational framework for discontinuous modelling of masonry arch bridges. Computer \& Structures, 79, 1821-30. 
Wang, J. (2004). The three-dimensional behaviour of masonry arches, PhD Thesis, University of Salford.

Zhang, Y., Macorini, L., \& Izzuddin, B.A. (2016). Mesoscale partitioned analysis of brick-masonry arches. Engineering Structures, 124, 142-166. 


\section{List of Figures}

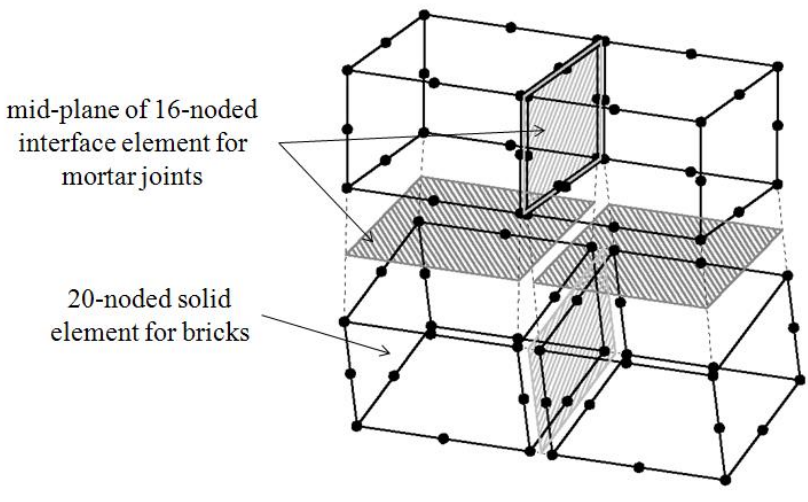

(a)

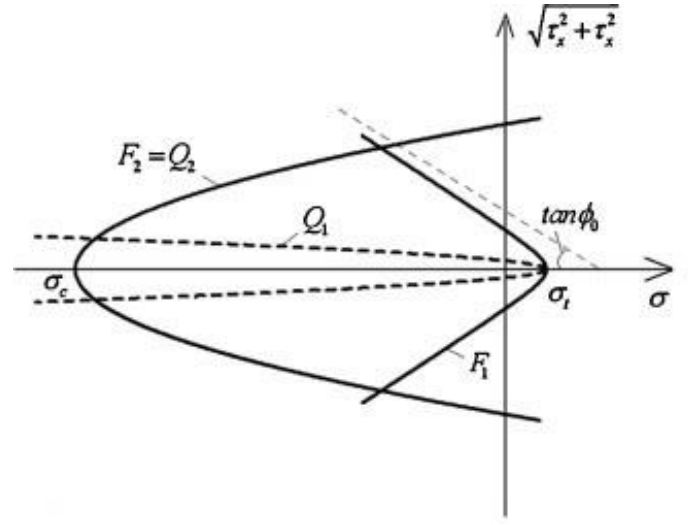

(b)

Figure 1. Masonry mesoscale description (Macorini \& Izzuddin, 2011): (a) solid elements connected by nonlinear interfaces, (b) yield functions and plastic potentials 


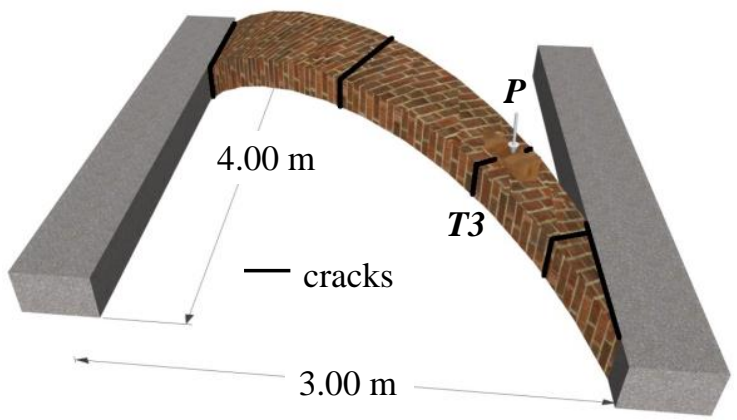

(a)
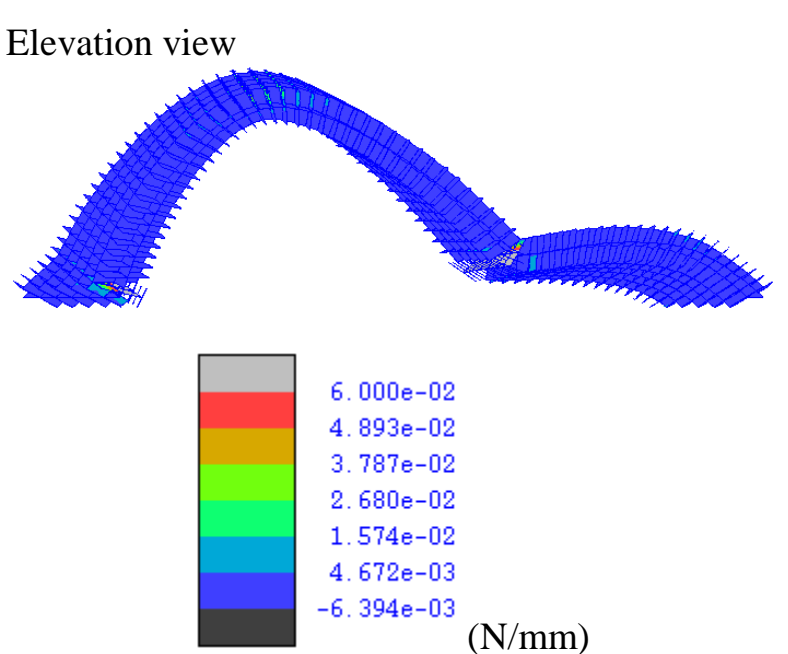

6. $000 \mathrm{e}-02$

4. $893 \mathrm{e}-02$

3. $787 e-02$

2. $680 \mathrm{e}-02$

1. $574 \mathrm{e}-02$

4. $672 \mathrm{e}-03$

$-6.394 e-03$

$(\mathrm{N} / \mathrm{mm})$

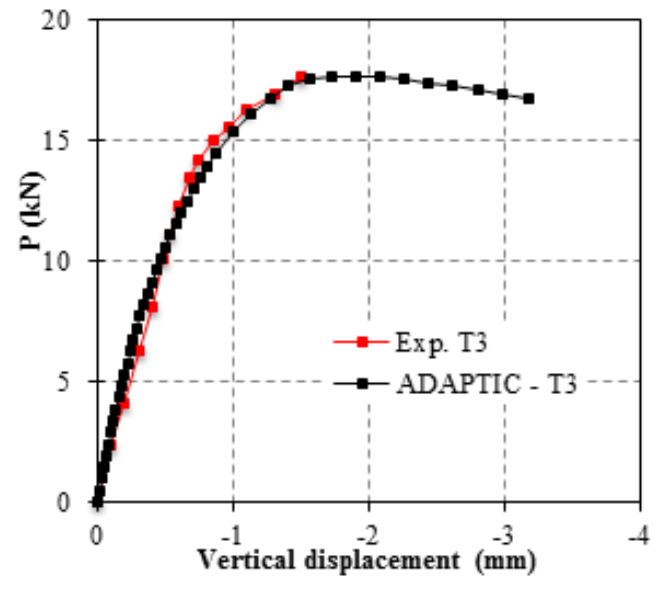

(b)

Plan view
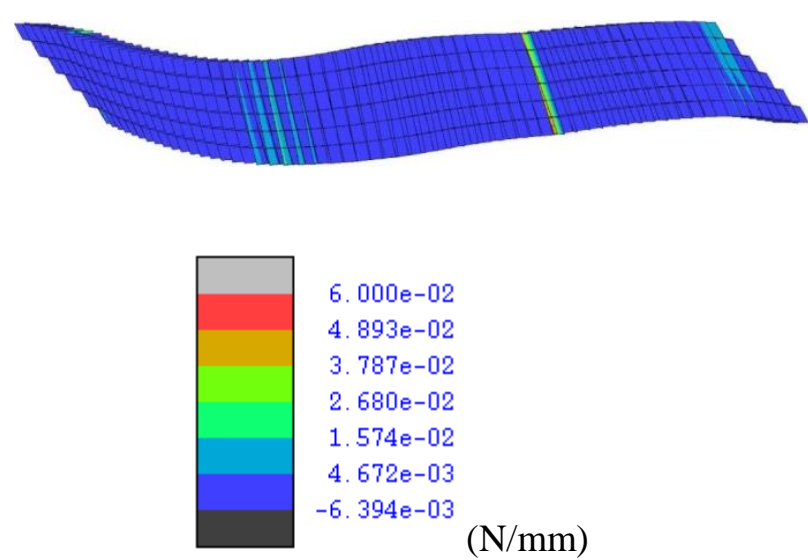

6. $000 \mathrm{e}-02$

4. $893 \mathrm{e}-02$

3. $787 \mathrm{e}-02$

2. $680 \mathrm{e}-02$

1. $574 \mathrm{e}-02$

$4.672 \mathrm{e}-03$

$-6.394 e-03$

(N/mm)

Failure mode $P=17.65 \mathrm{kN}$

(c)

Figure 2. Numerical-experimental comparison on a skew arch (Zhang et al., 2016): (a) geometric characteristics, loading arrangement and experimental cracks, (b) experimentalnumerical load-displacement curves, (c) plastic work contour at ultimate load 


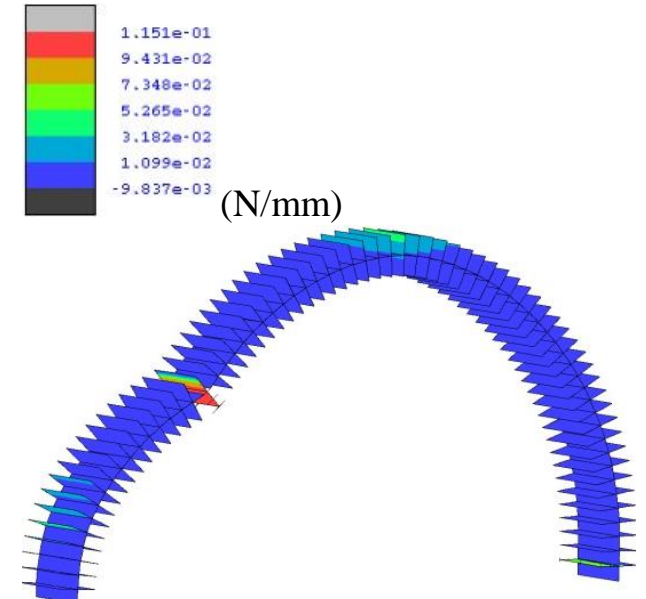

(a) $\operatorname{Arch} 1$
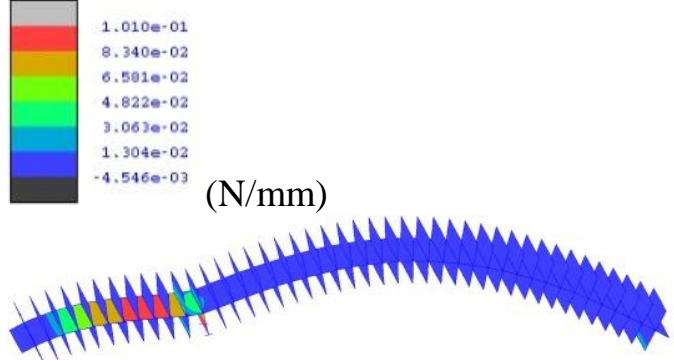

(c) Arch 3

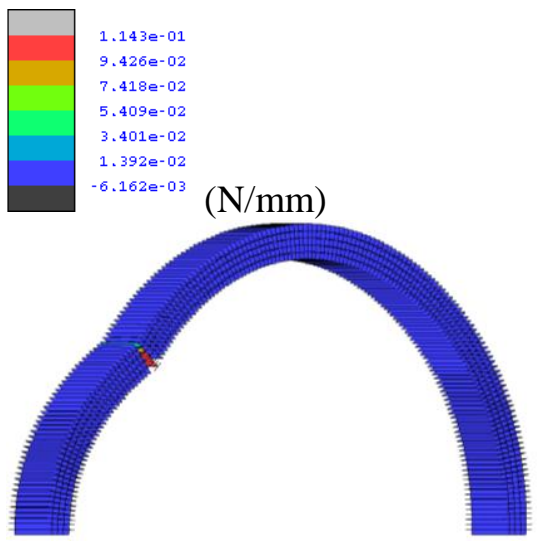

(e) $\operatorname{Arch} 5$

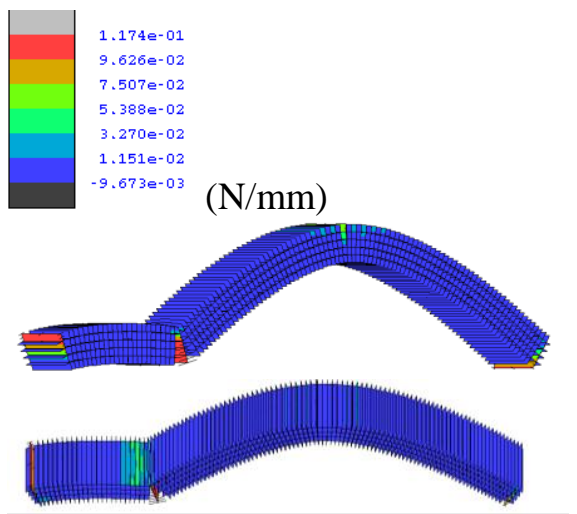

(g) Arch 7
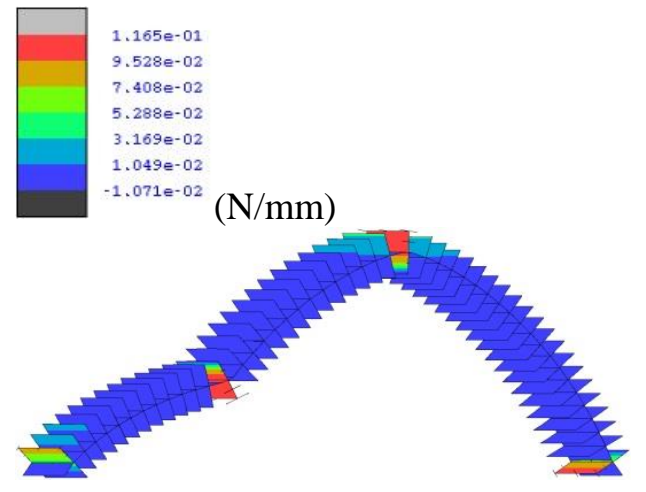

(b) Arch 2
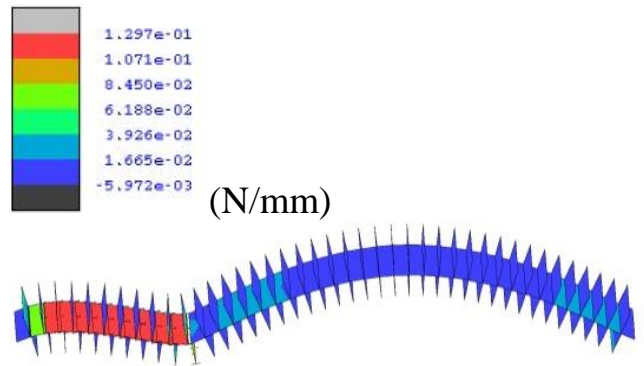

(d) $\operatorname{Arch} 4$

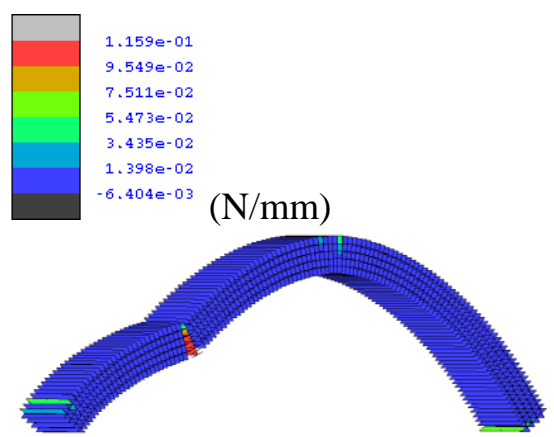

(f) $\operatorname{Arch} 6$

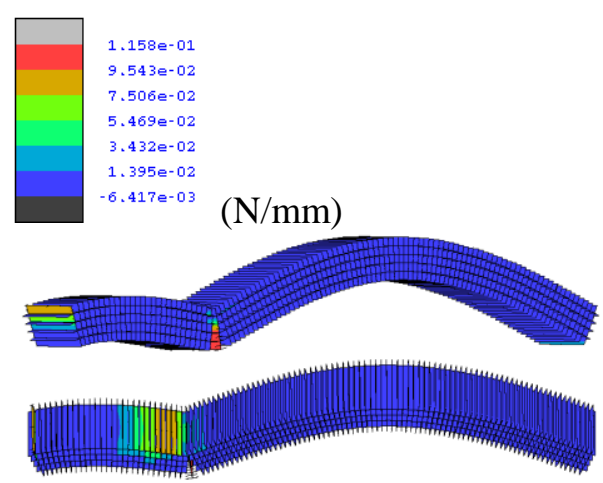

(h) $\operatorname{Arch} 8$

Figure 3. Interface plastic work Wcrl contour at the last step of analysis for arches with different rise-to-span ratios 


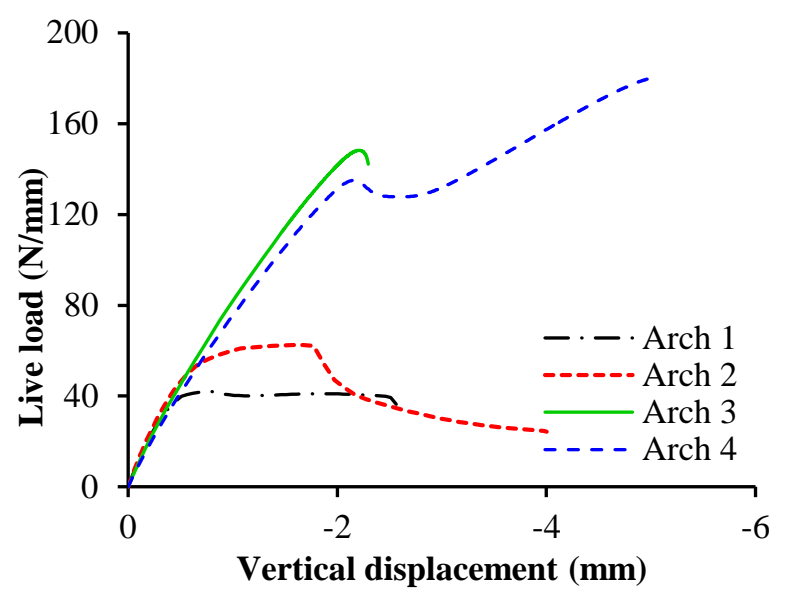

(a)

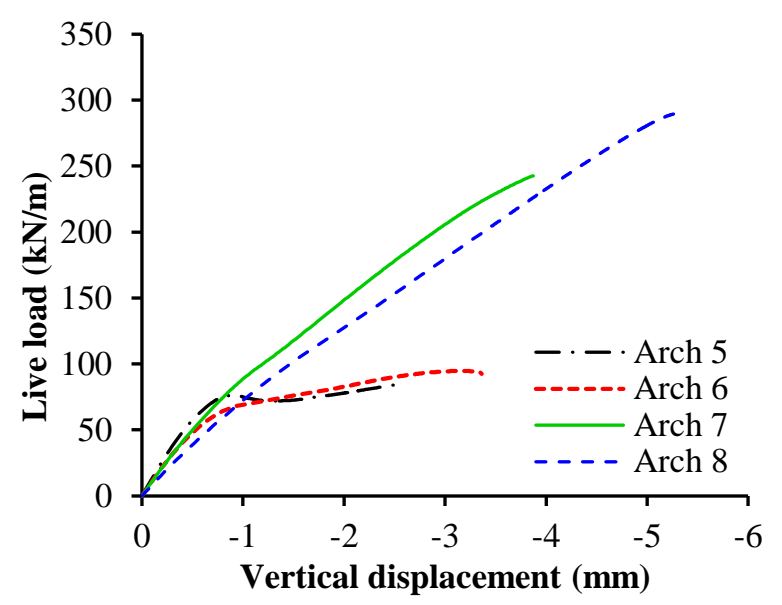

(b)

Figure 4. Load-displacement curves at quarter span for arches with different rise-to-span ratios: (a) 3m-span arch, (b) 8m-span arch
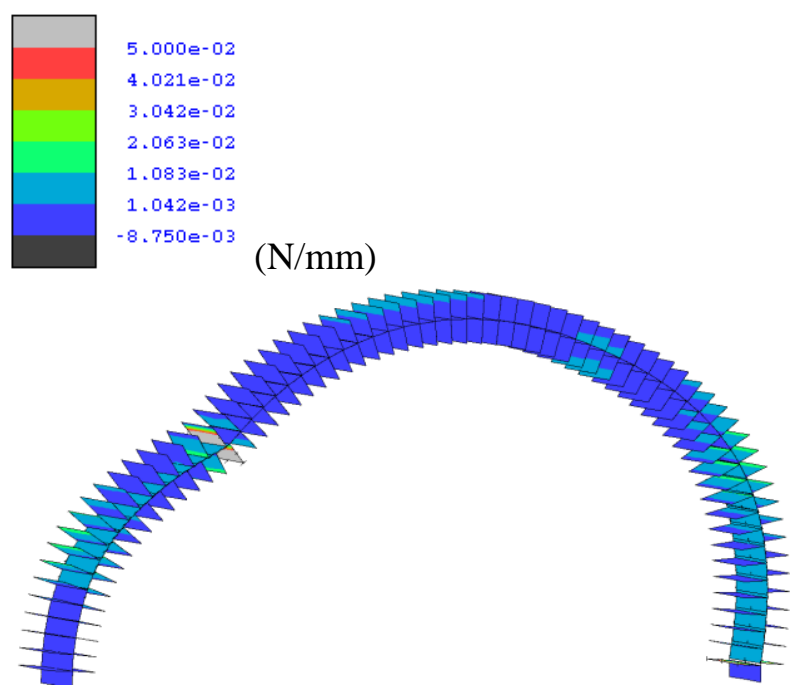

(a) Rise-to-span ratio $=1: 2$
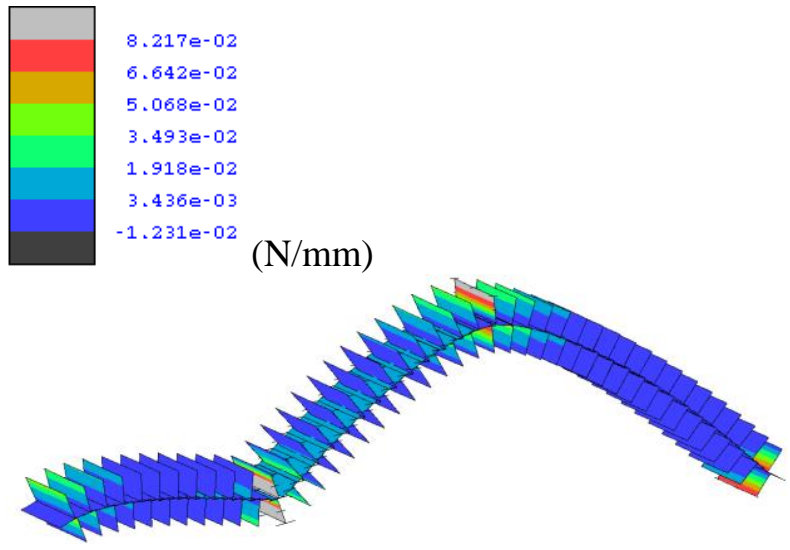

(c) Rise-to-span ratio $=1: 8$
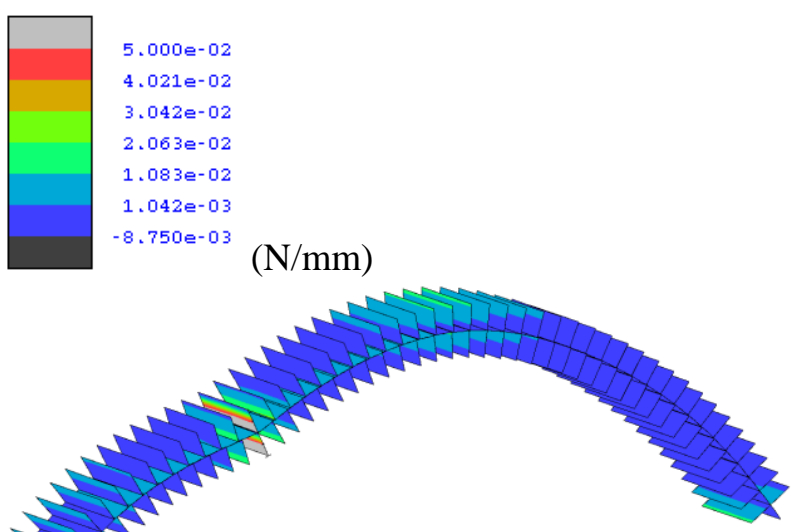

(b) Rise-to-span ratio $=1: 4$
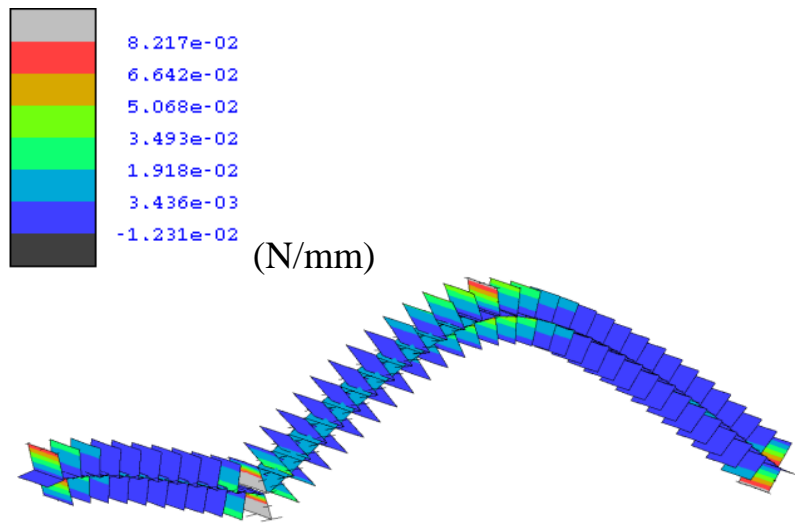

(d) Rise-to-span ratio $=1: 10$

Figure 5. Plastic work $W_{c r l}$ contour at the last step of analysis for defective arches 


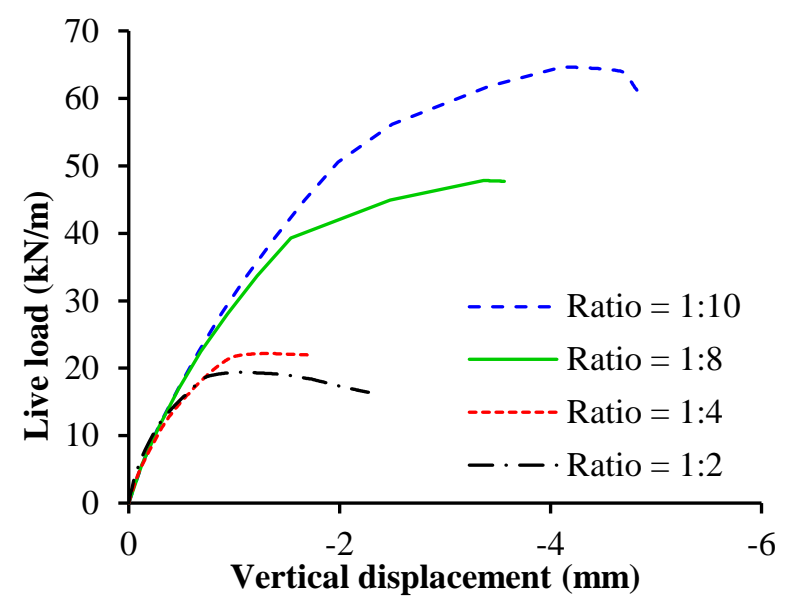

Figure 6. Load displacement curves for defective arches with different rise-to-span ratios

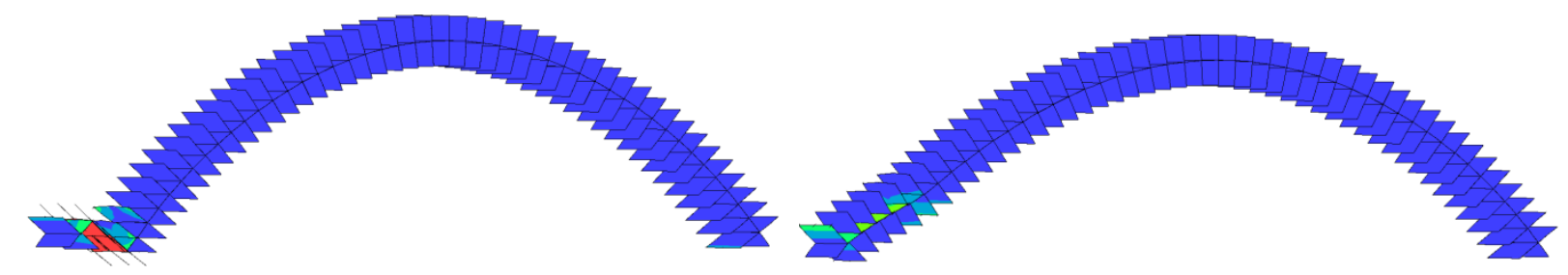

(a) Arch 2 - Case 1

(b) Arch 2 - Case 2

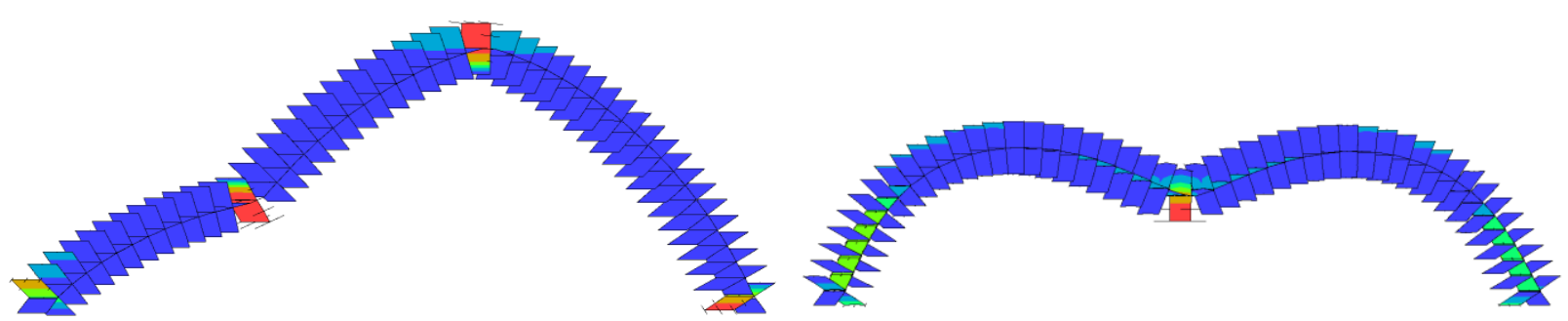
(c) Arch 2 - Case 3
(c) Arch 2 - Case 4

Figure 7. Interface plastic work $W_{c r 1}(\mathrm{~N} / \mathrm{mm})$ of Arch 2 at the last step of analysis for different live load positions 


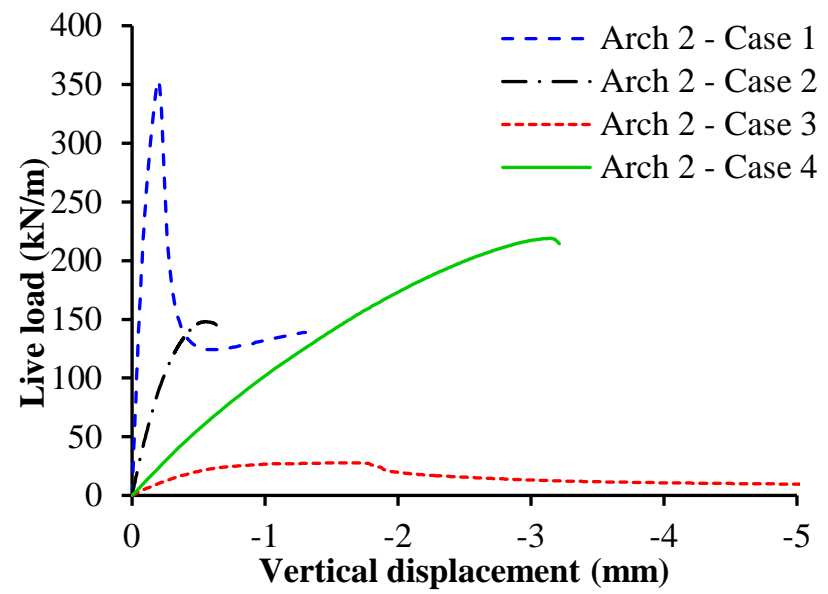

(a)

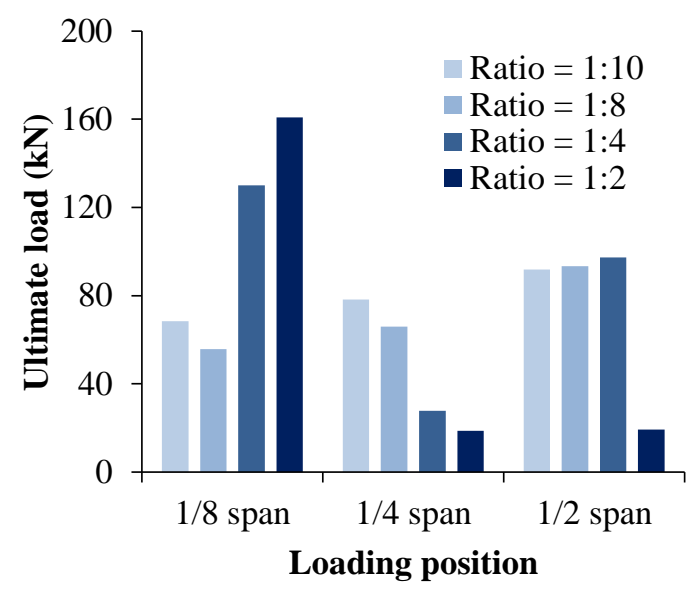

(b)

Figure 8. Influence of loading position on (a) load-displacement curves for Arch $2(b)$ ultimate load of arches with different rise-to-span ratios

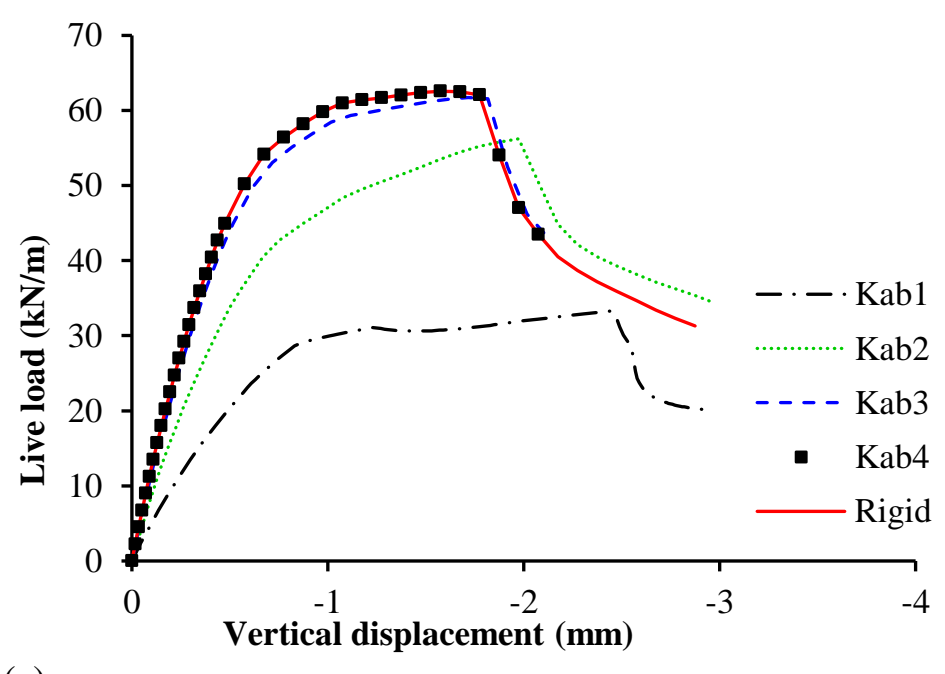

(a)
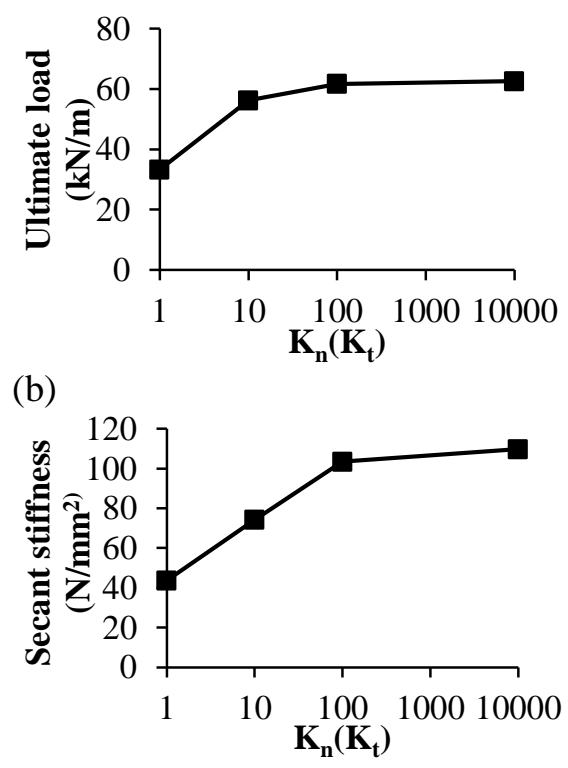

(c)

Figure 9. Influence of abutment stiffness on Arch 2 


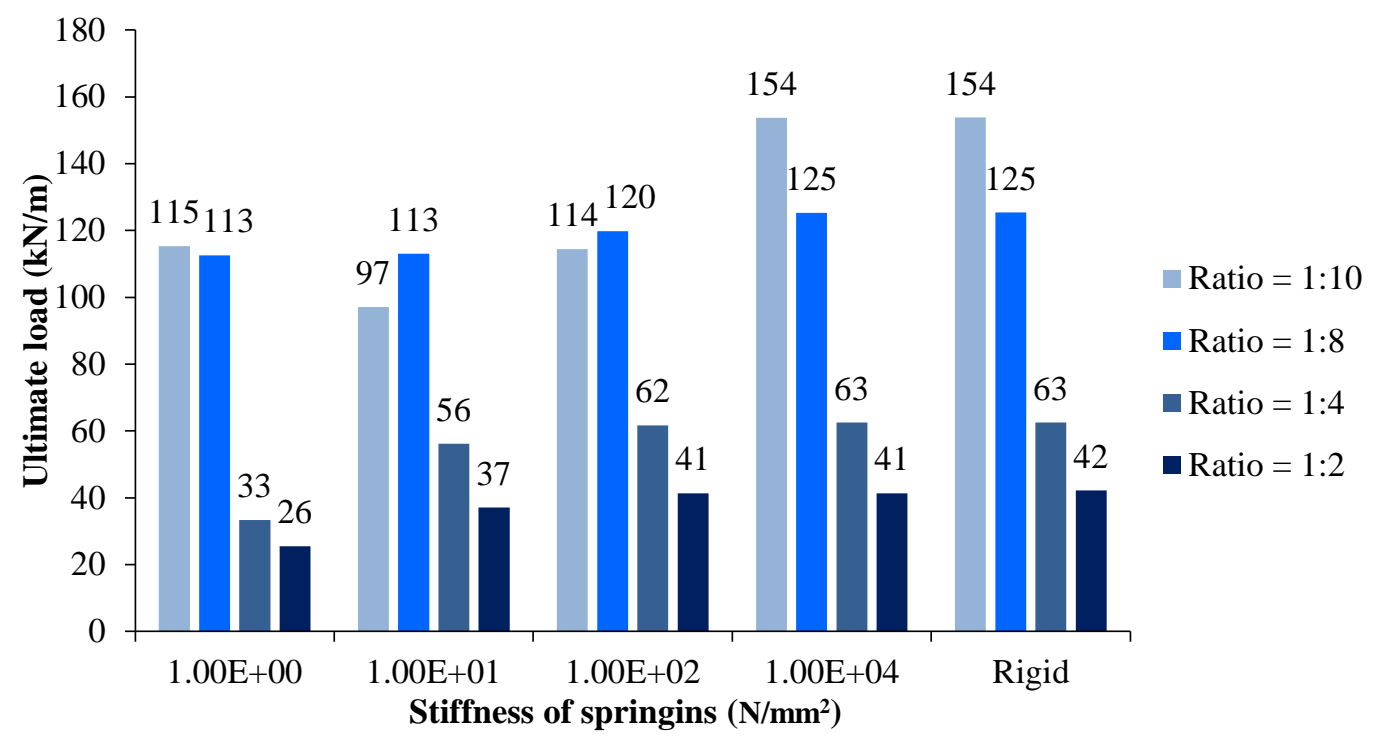

(a)

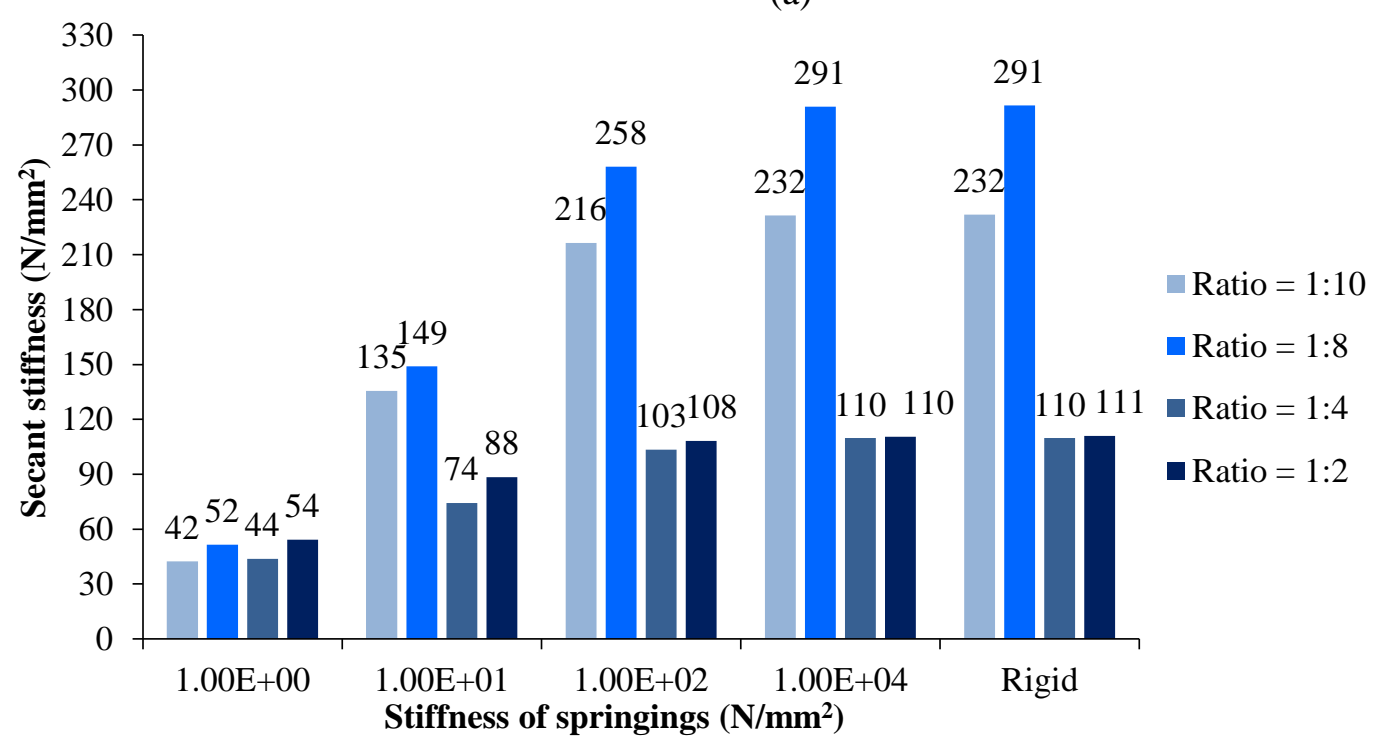

(b)

Figure 10. Influence of the abutment stiffness on (a) the ultimate load and (b) the secant stiffness for arches with different rise-to-span ratios 


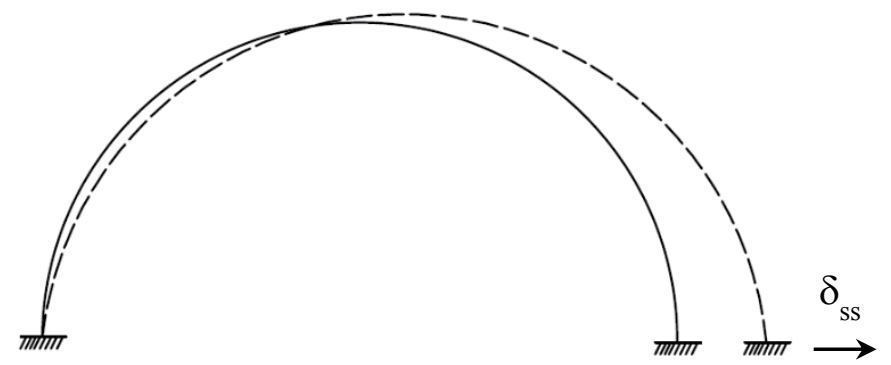

Horizontal spread of support $\delta_{\mathrm{ss}}$

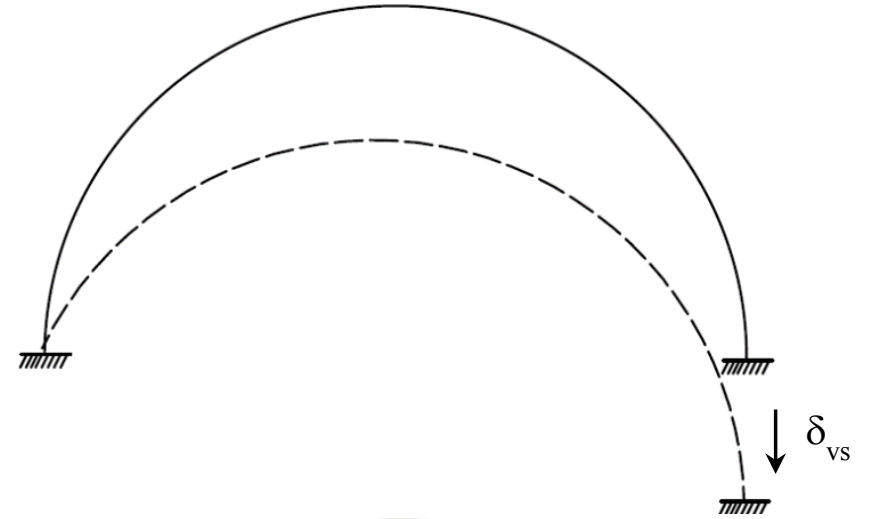

Vertical differential settlement $\delta_{\mathrm{sv}}$

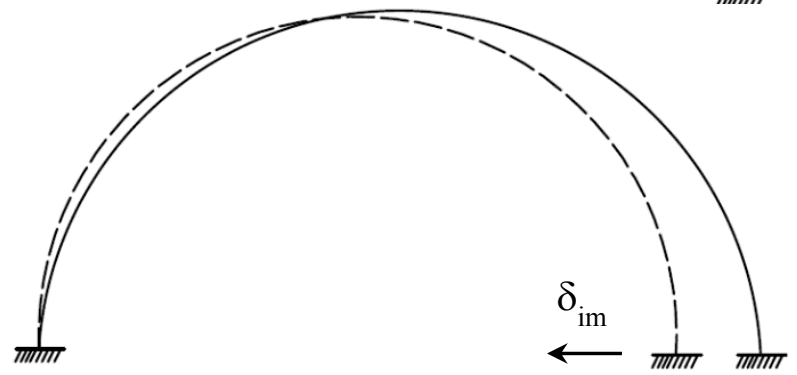

Horizontal inward movement $\delta_{\text {im }}$

Figure 11. Settlement modes considered in the numerical analyses 

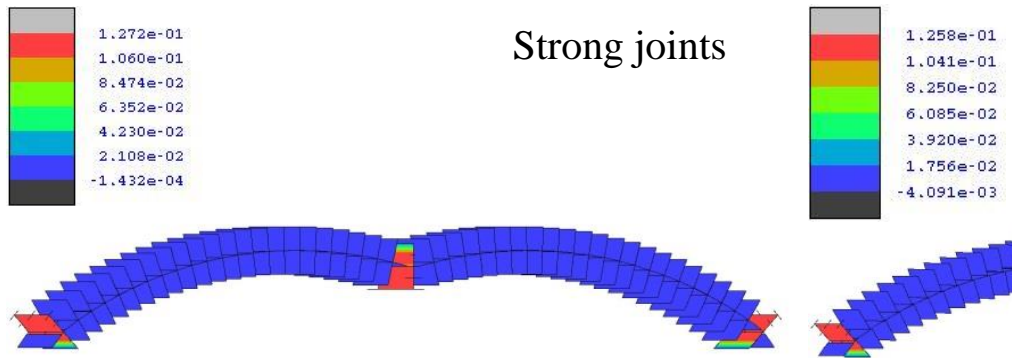

Weak joints

(a) Horizontal spread of support

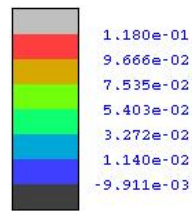

Strong joints
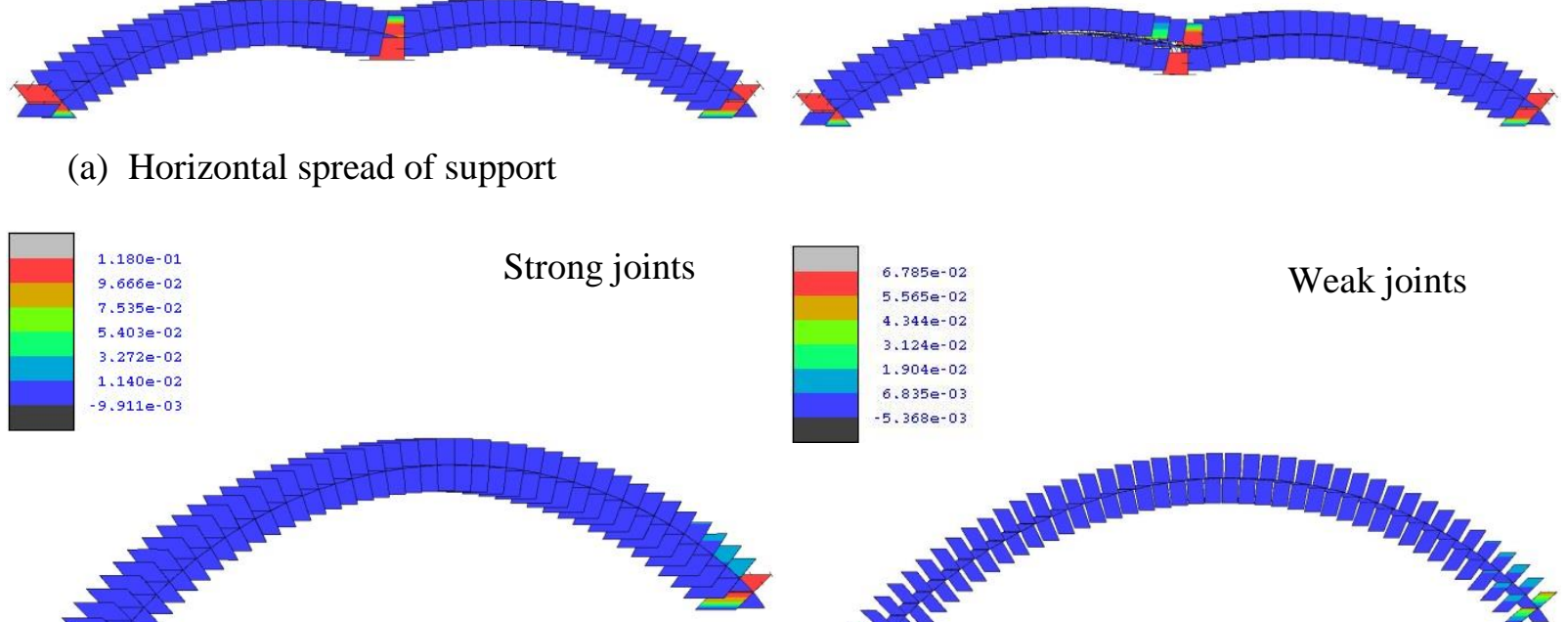

Weak joints

. $666 \mathrm{e}-02$

7.535e-02

$3.272 \mathrm{e}-02$

$1.140 \mathrm{e}-02$

$911 \mathrm{e}^{-03}$

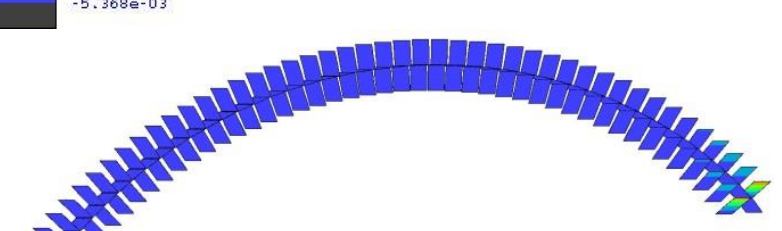

5

(b) Vertical differential settlement

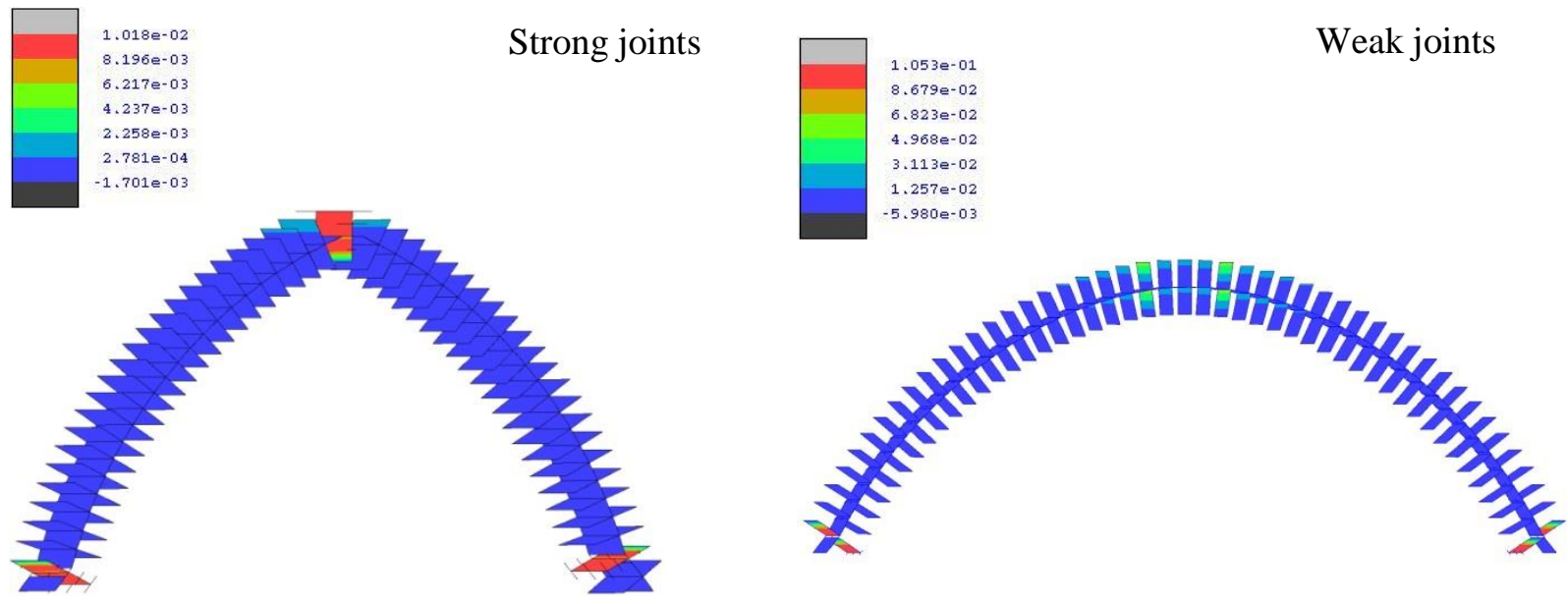

(c) Horizontal inward movement

Figure 12. Plastic work $W_{c r 1}(\mathrm{~N} / \mathrm{mm})$ contour at the last step of the numerical simulations considering different settlement modes for Arch 2 with strong or weak circumferential mortar joints 


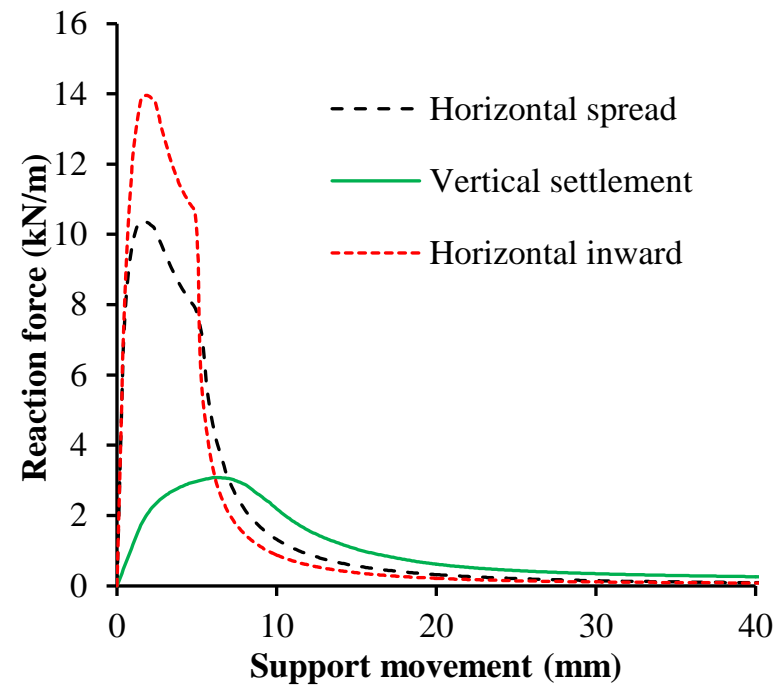

(a) Strong joints

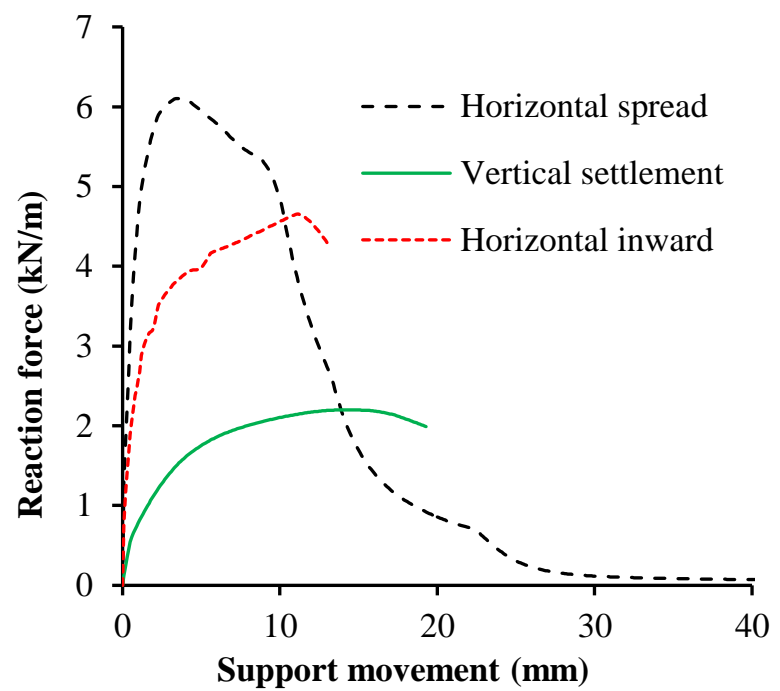

(b) Weak joints

Figure 13. Reaction force-support displacement curves for Arch 2 with different brick work

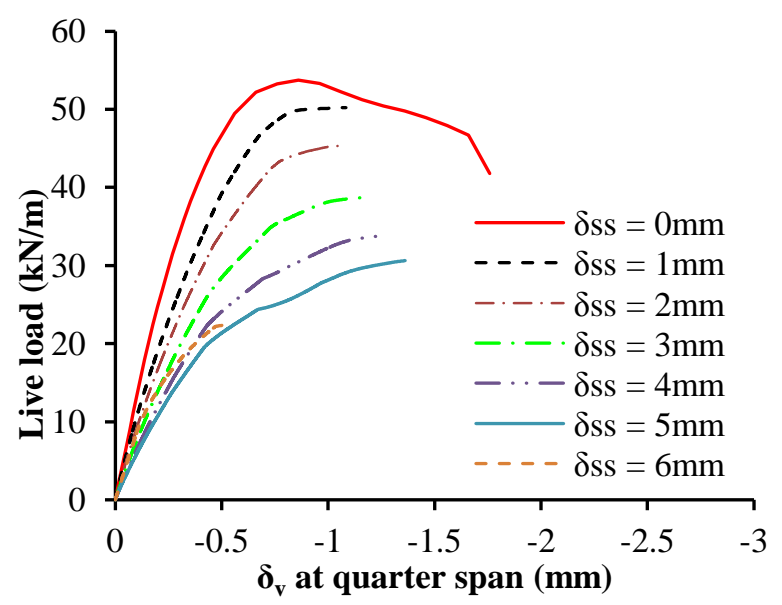

(a) L-D curves for arches with strong joints

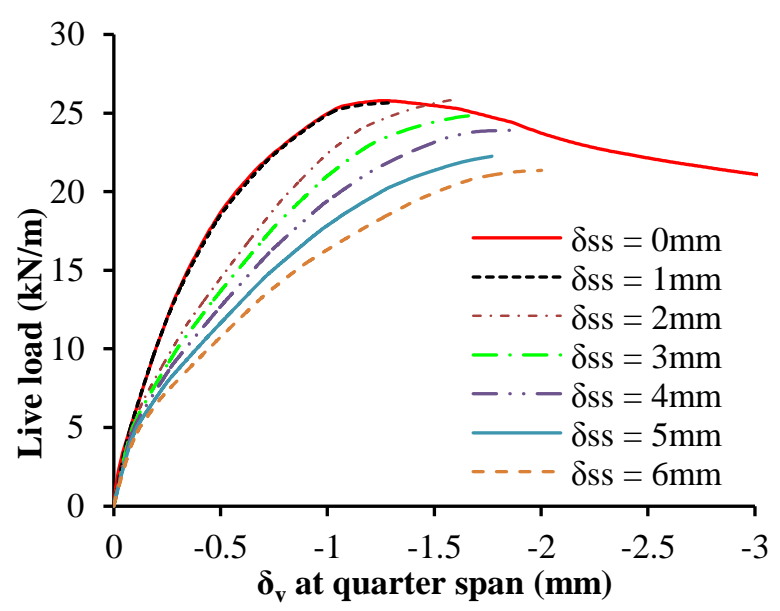

(b) L-D curves for arches with weak joints

Figure 14. Effects of horizontal spread of support 

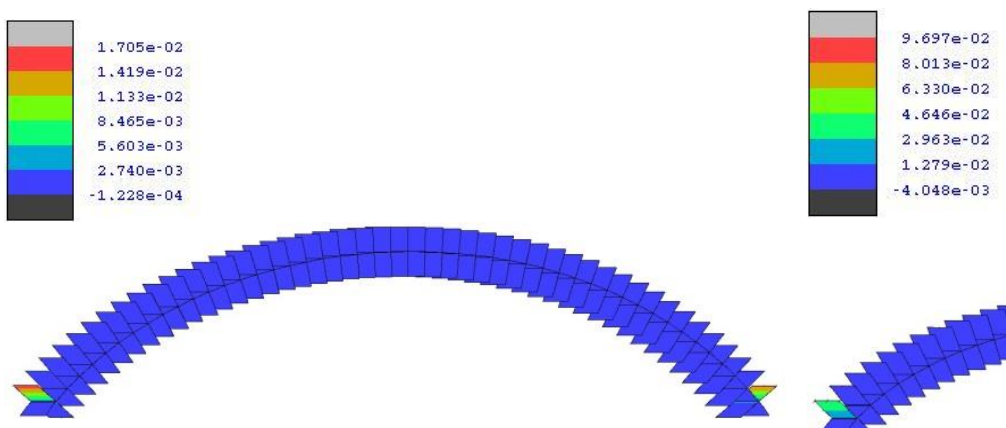

(a) $\delta_{\mathrm{ss}}=1 \mathrm{~mm}$
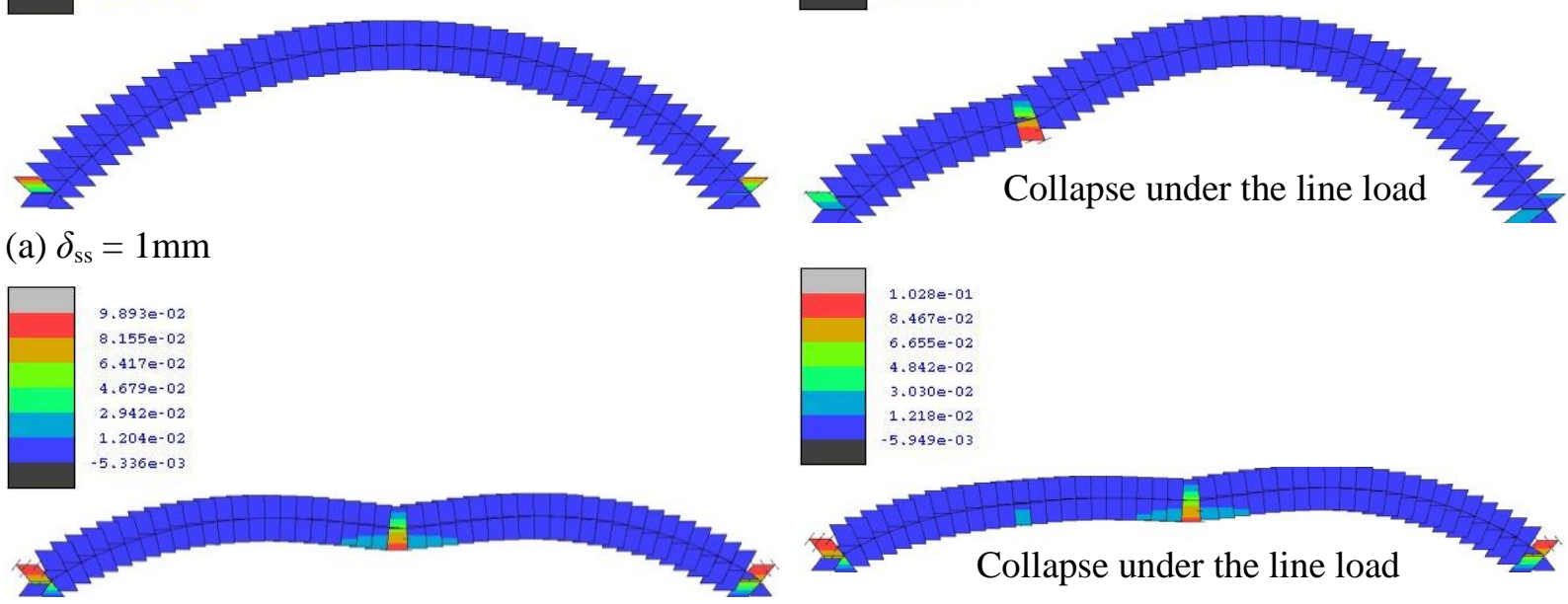

(b) $\delta_{\mathrm{ss}}=6 \mathrm{~mm}$

Figure 15. Plastic work $W_{c r 1}(\mathrm{~N} / \mathrm{mm})$ contours for Arch 2 at (a) $\delta_{s s}=1 \mathrm{~mm}$ and $(b) \delta_{s s}=6 \mathrm{~mm}$

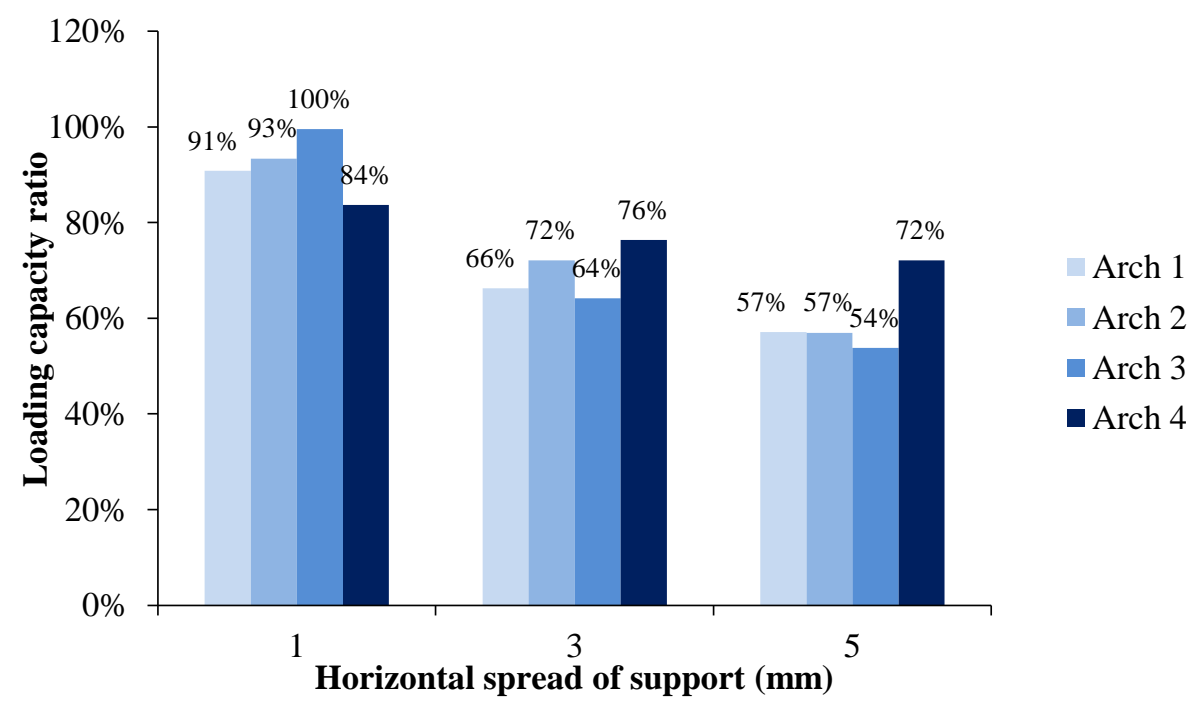

Figure 16. Loading capacity for different values of horizontal spread of abutment for arches with different rise-to-span ratio 


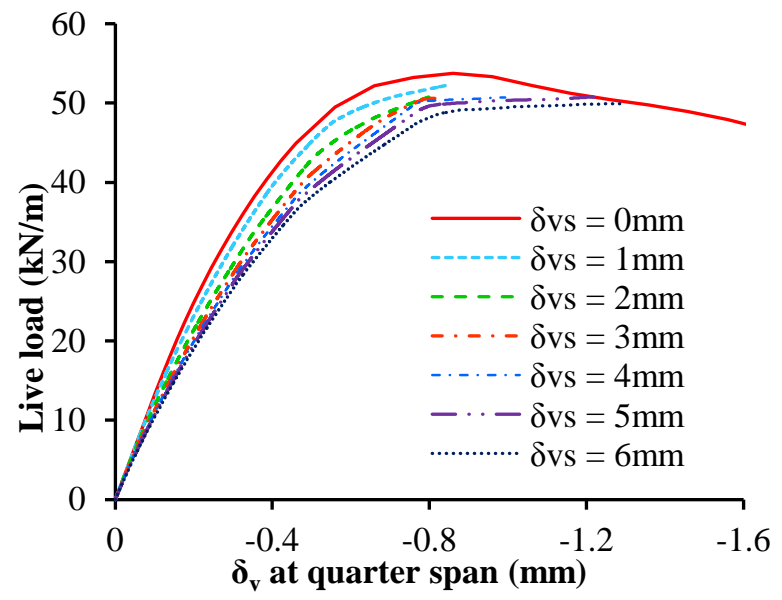

(a) L-D curves for arches with strong joints

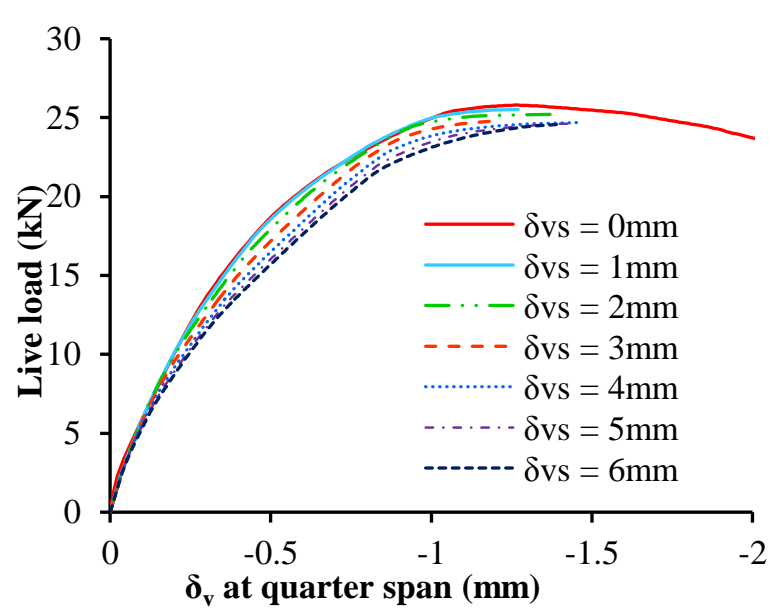

(b) L-D curves for arches with weak joints

Figure 17. Effects of vertical settlement of support

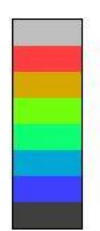

$0.000 e+00$

$0.000 e+00$

$0.000 e+00$

$0.000 e+00$

$0.000 \mathrm{e}+00$

$0.000 e+00$

$0.000 e+00$

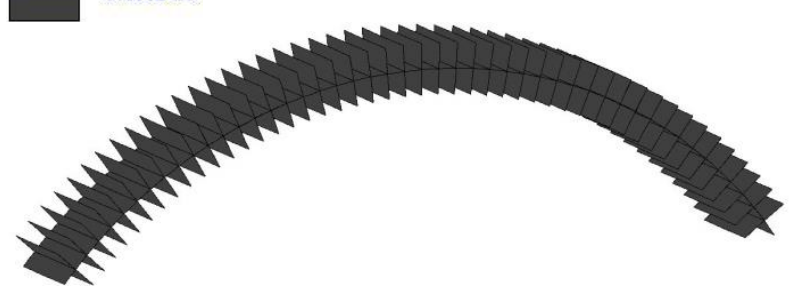

(a) $\delta_{\mathrm{vs}}=1 \mathrm{~mm}$
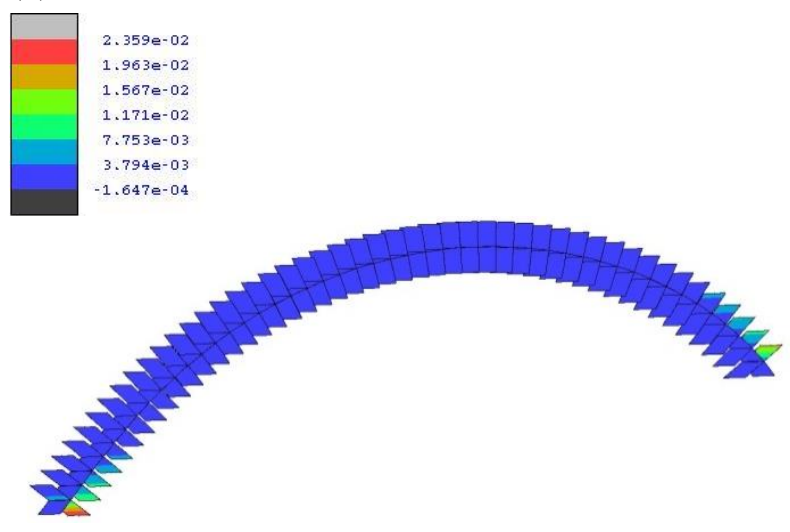
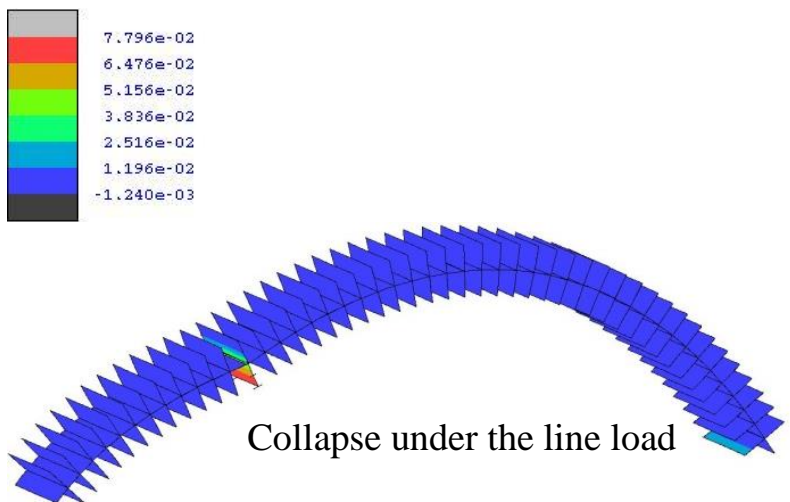

Collapse under the line load

(b) $\delta_{\mathrm{vs}}=6 \mathrm{~mm}$
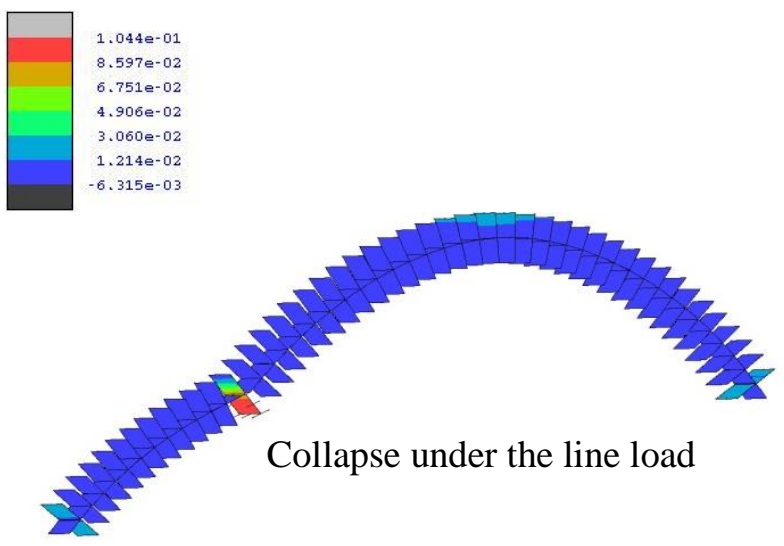

Figure 18. Plastic work $W_{c r l}(\mathrm{~N} / \mathrm{mm})$ contours for Arch 2 at $(a) \delta_{v s}=1 \mathrm{~mm}$ and $(b) \delta_{v s}=6 \mathrm{~mm}$ 


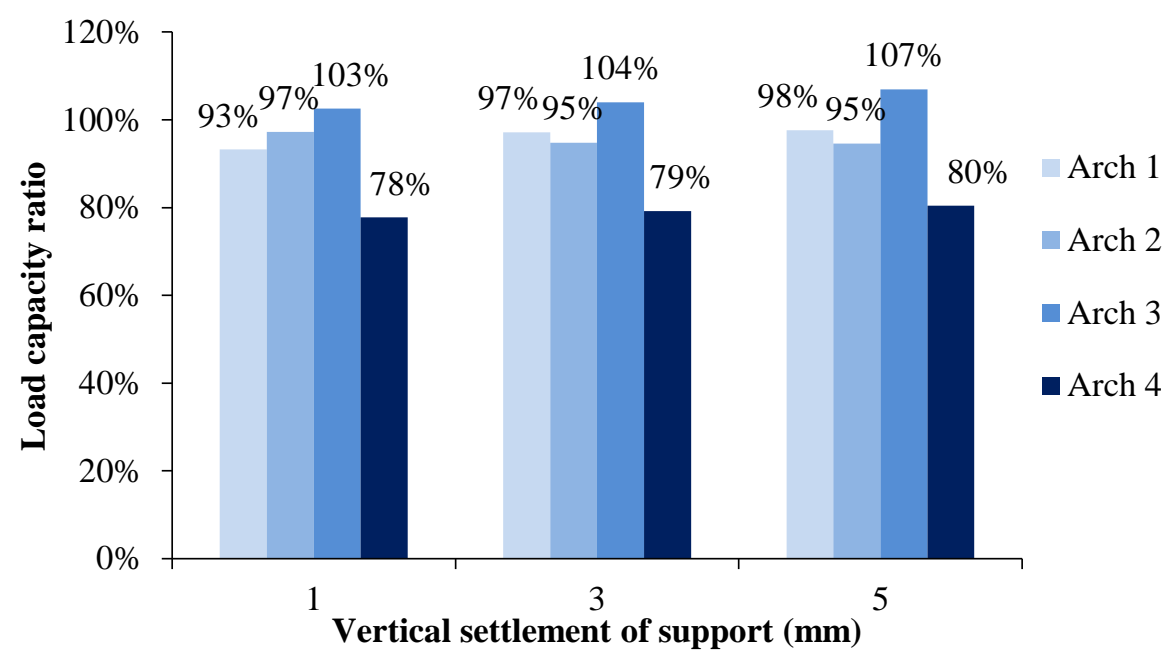

Figure 19. Load capacity ratio for different values of vertical settlement for arches with different rise-to-span ratio

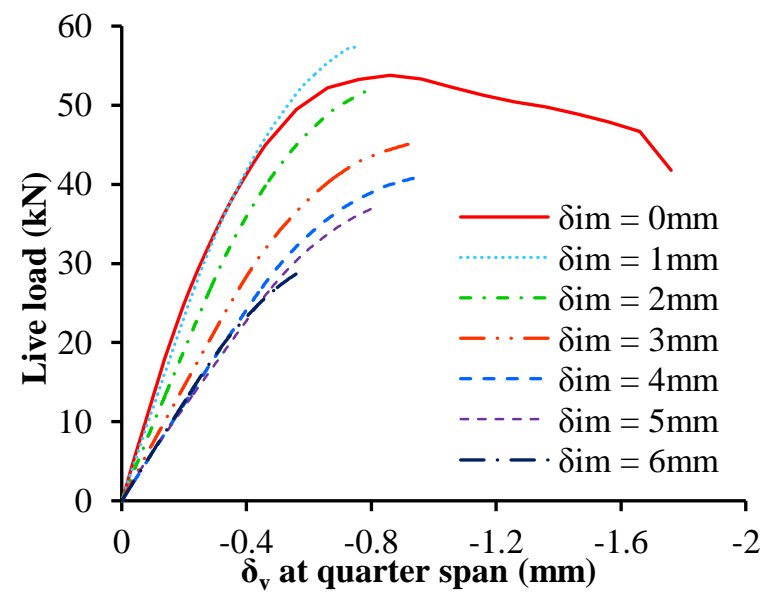

(a) L-D curves for arches with strong joints

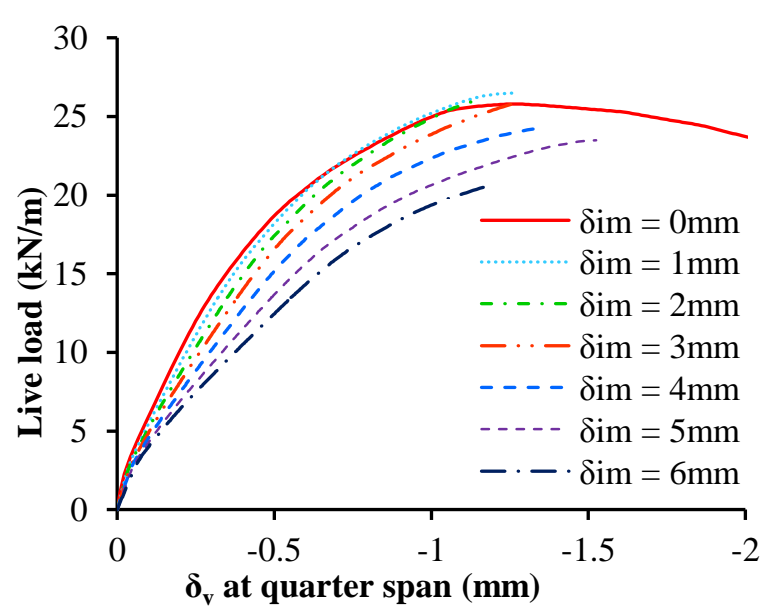

(b) L-D curves for arches with weak joints

Figure 20. Effect of horizontal inward support displacement 


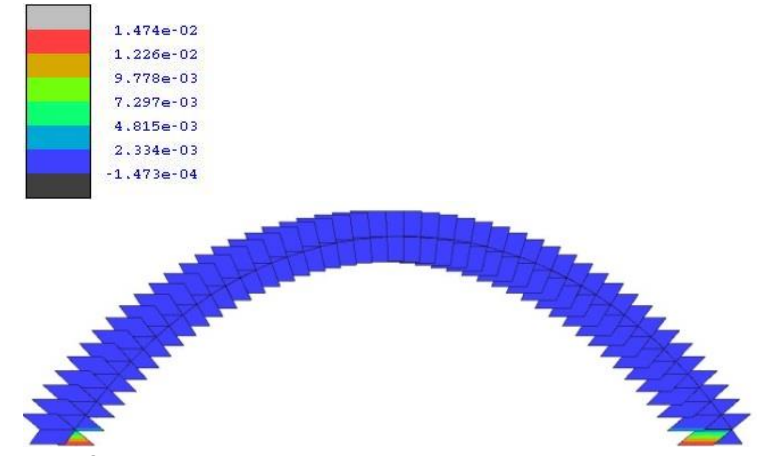

(a) $\delta_{\text {im }}=1 \mathrm{~mm}$
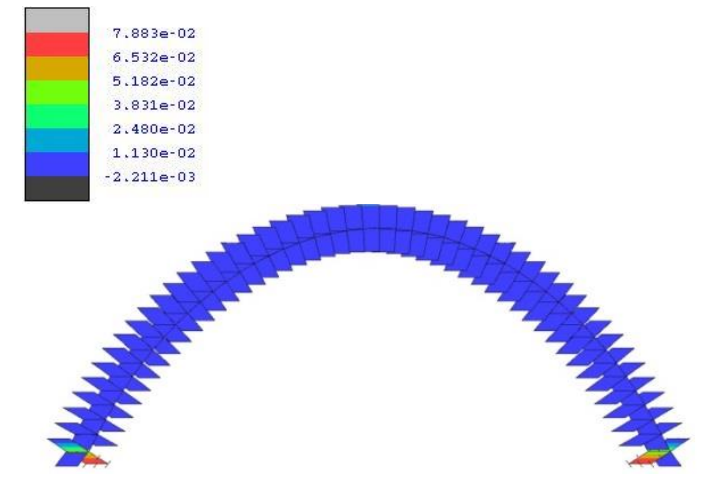

(b) $\delta_{\text {im }}=6 \mathrm{~mm}$

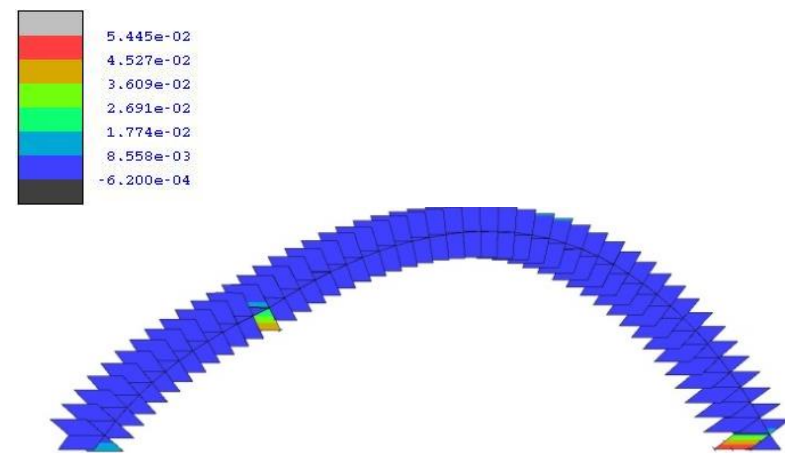

Collapse under the line load

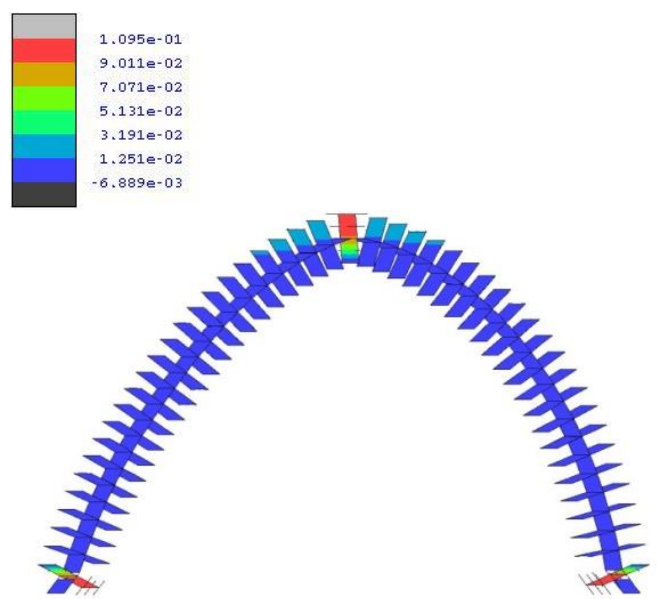

Collapse under the line load

Figure 21. Plastic work $W_{c r l}(\mathrm{~N} / \mathrm{mm})$ contours for Arch 2 at $(a) \delta_{i m}=1 \mathrm{~mm}$ and $(b) \delta_{i m}=$ $6 m m$

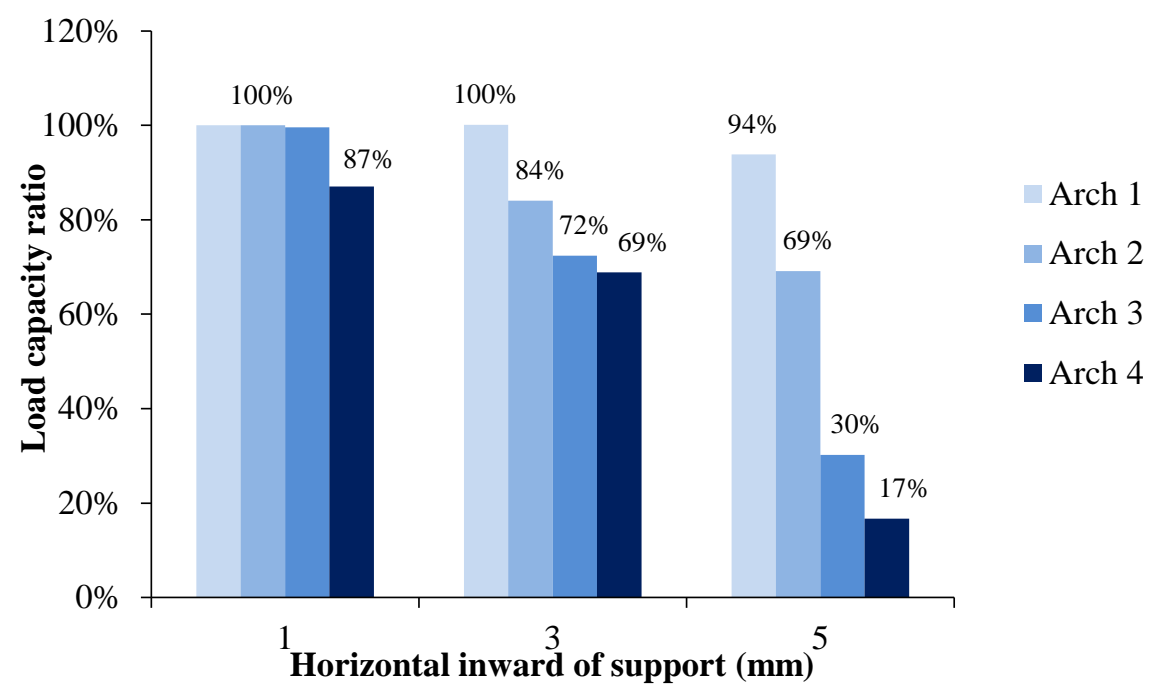

Figure 22. Load capacity ratio for different values of horizontal support displacement for arches with different rise-to-span ratio 


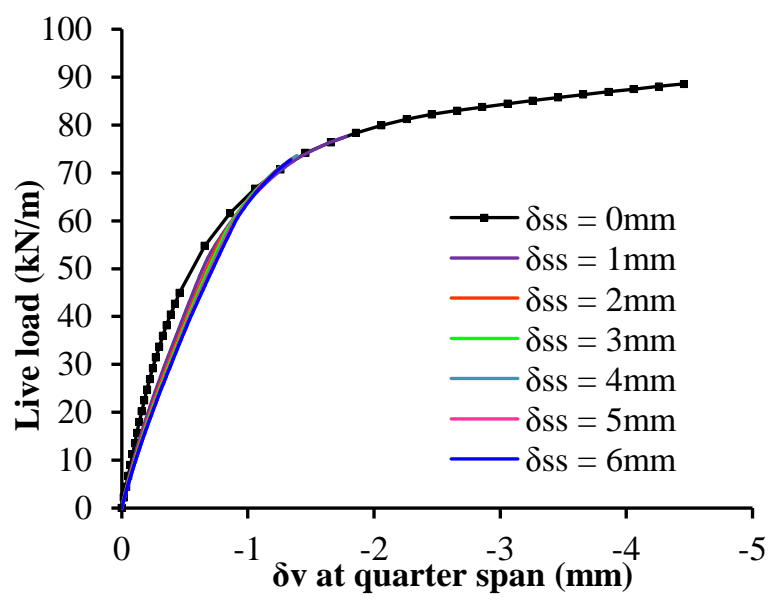

(a) Arch with horizontal spread of support

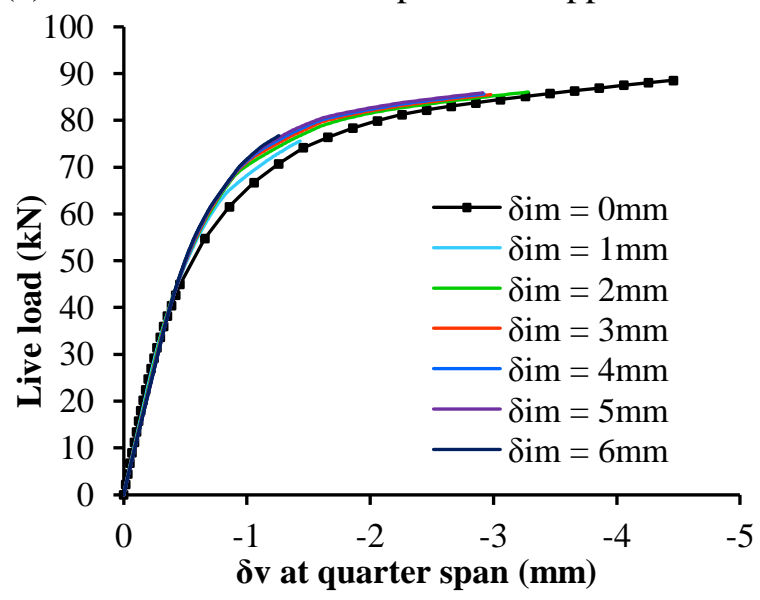

(c) Arch with horizontal inward support displacement

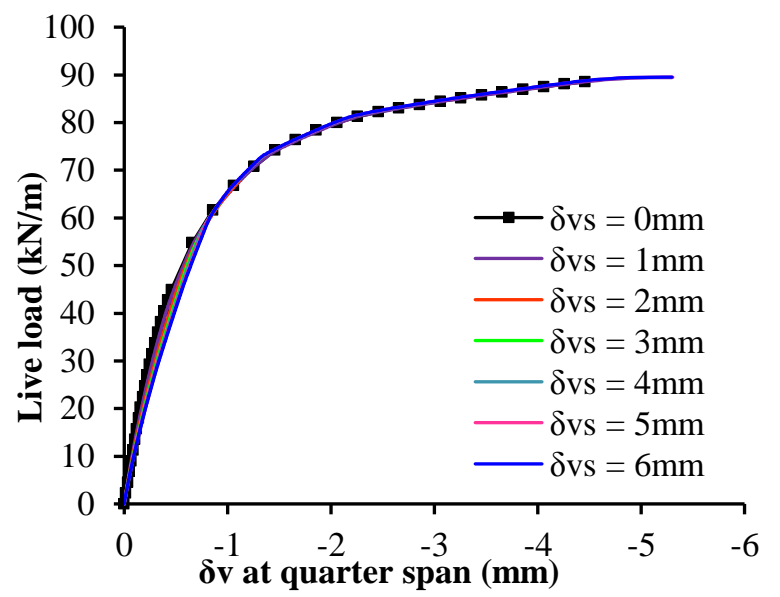

(b) Arch with vertical support settlement

Figure 23. Load-displacement curve analysis for different settlement of left support

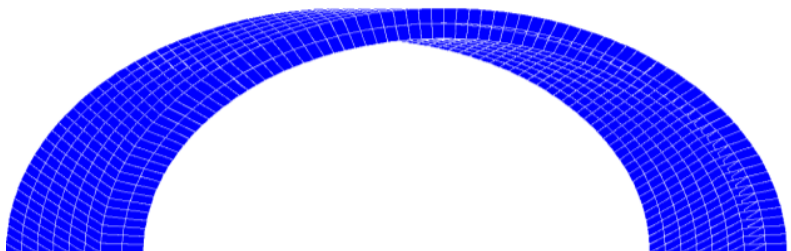

(a) Skew 1 - Ratio = 1:2

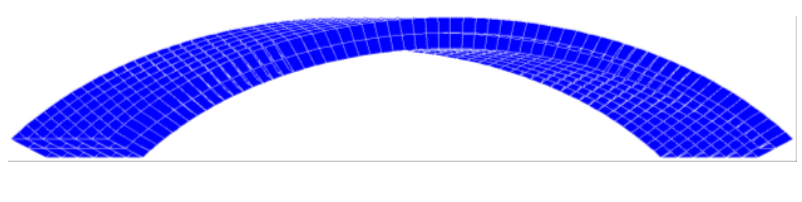

(b) Skew 2 - Ratio = 1:4

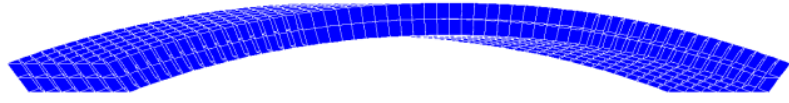

(c) Skew 3 - Ratio $=1: 8$

Figure 24. 3D mesoscale meshes for skew arches with different rise-to-span ratios 

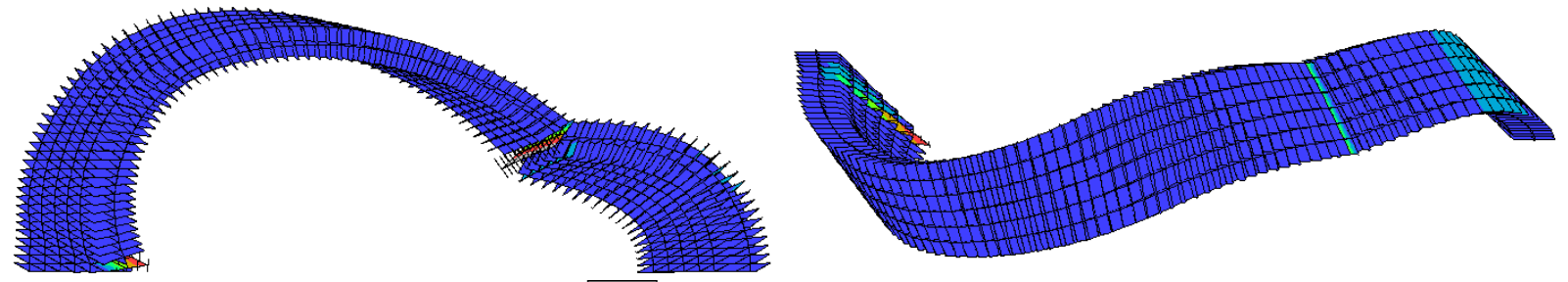

(a) Skew 1- Ratio = 1:2
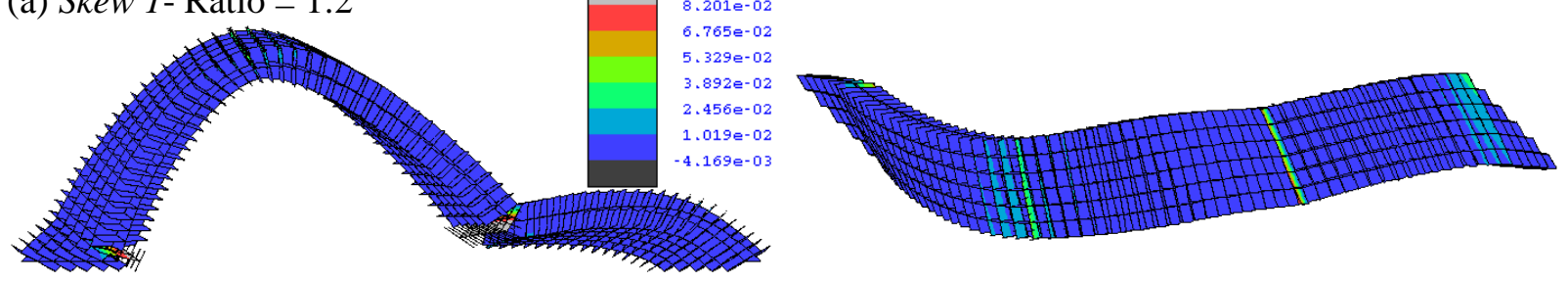

(b) Skew 2- Ratio = 1:4
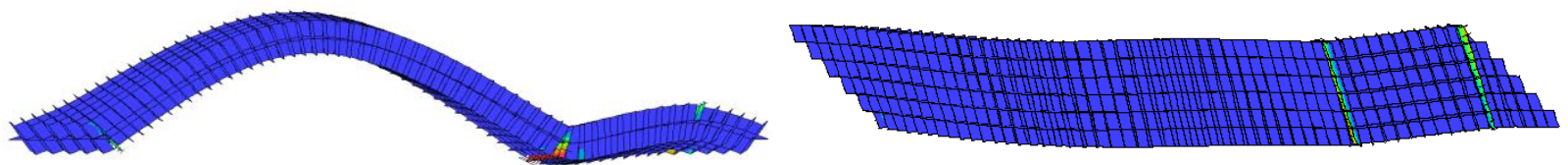

(c) Skew 3 - Ratio = 1:8

Figure 25. Plastic work $W_{c r l}(\mathrm{~N} / \mathrm{mm})$ contours at the last step of the analysis

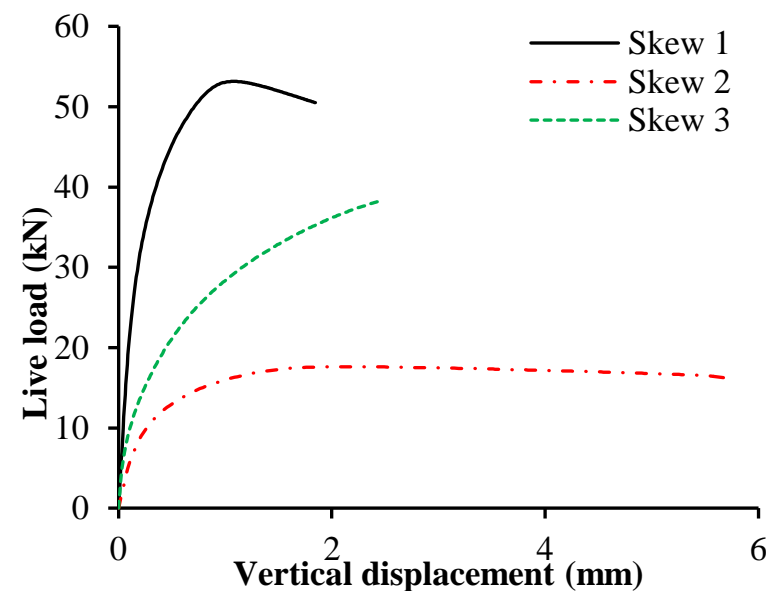

(a) L-D curves at $1 / 4$ span

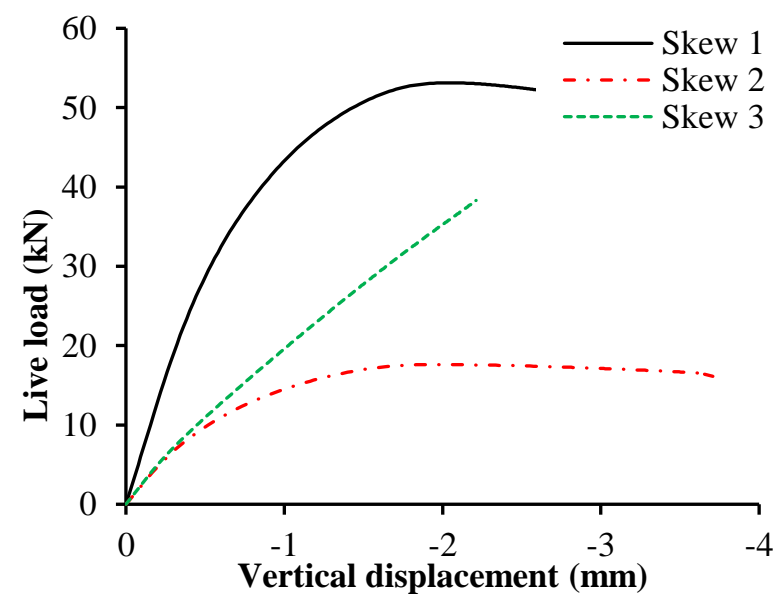

(b) L-D curves at 3/4 span

Figure 26. Load displacement curves at (a) 1/4 span and (b) 3/4 span for arches with different rise-to-span ratios 
(a) Header bond

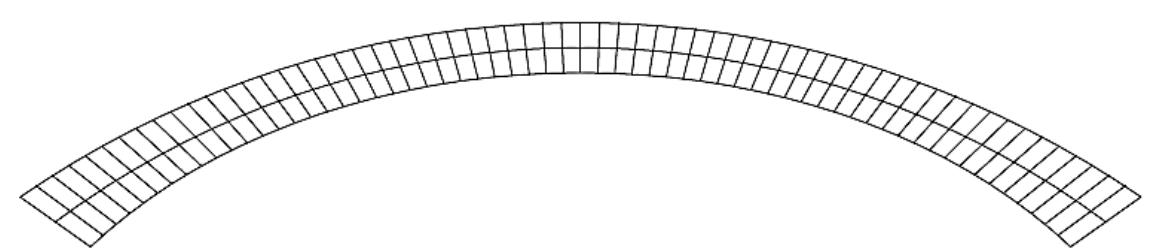

(b) Stretcher bond

Figure 27. Lateral view of skew arches showing the two alternative bond methods to connect adjacent rings

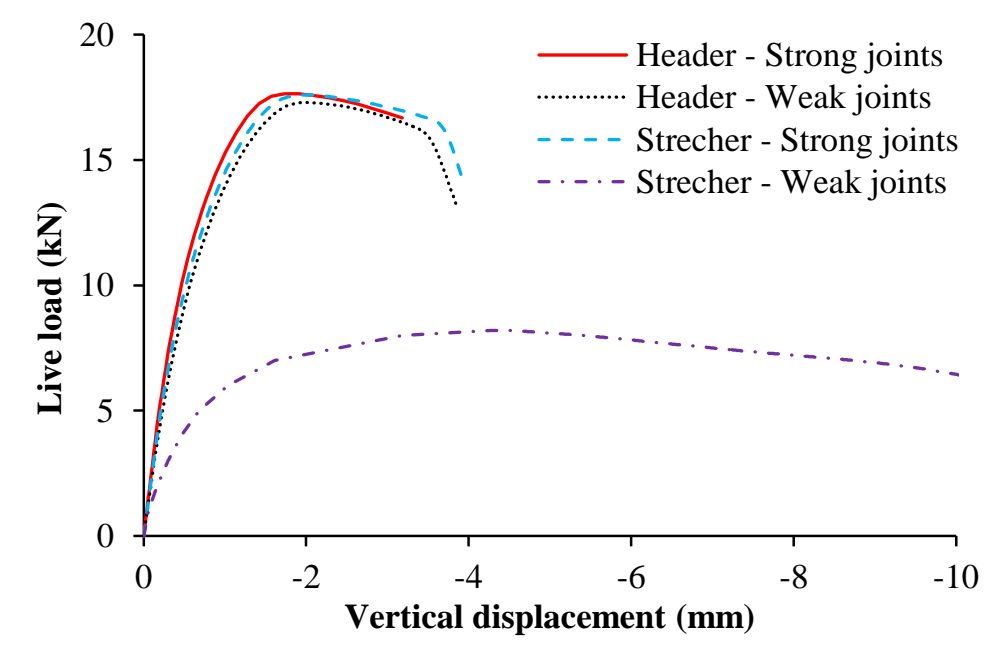

Figure 28. Numerical results for arches with 1:4 rise-to-span ratio and different circumferential joints 


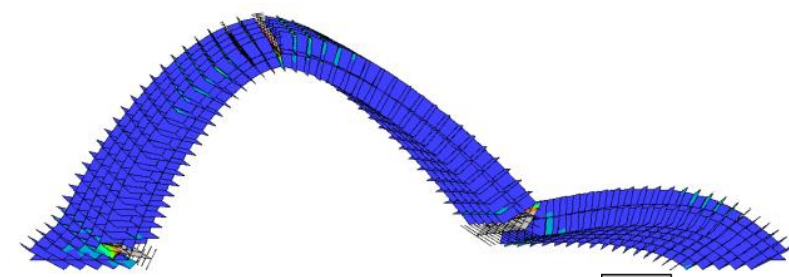

(a) Header bond - weak joints

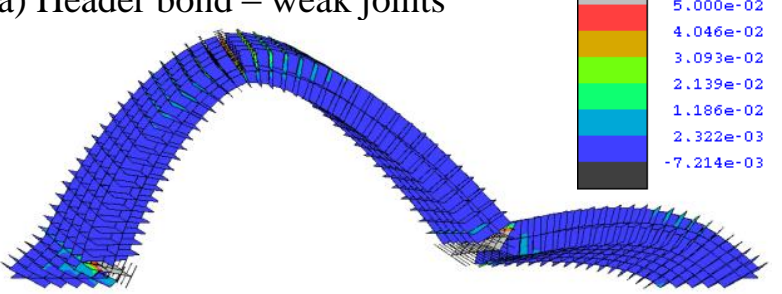

(b) Stretcher bond - strong joints

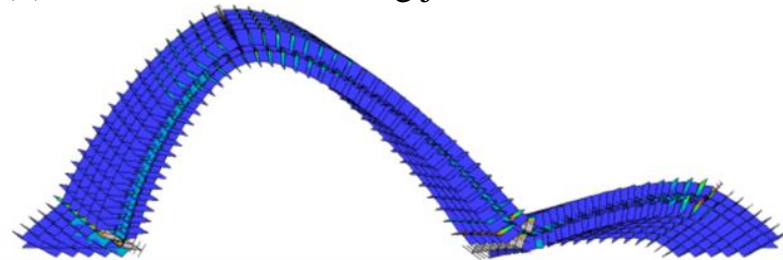

(c) Stretcher bond - weak joints
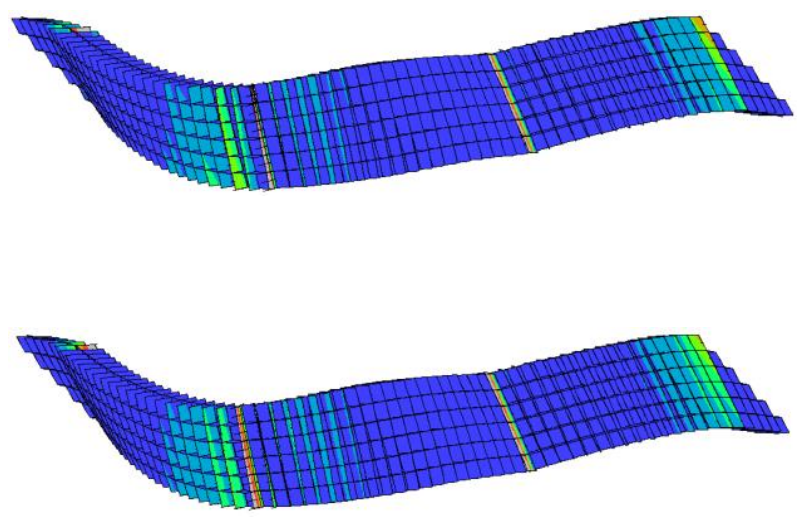

Figure 29. Interface plastic work $W_{c r l}(\mathrm{~N} / \mathrm{mm})$ contour for arches with 1:4 rise-to-span ratio and different circumferential joints

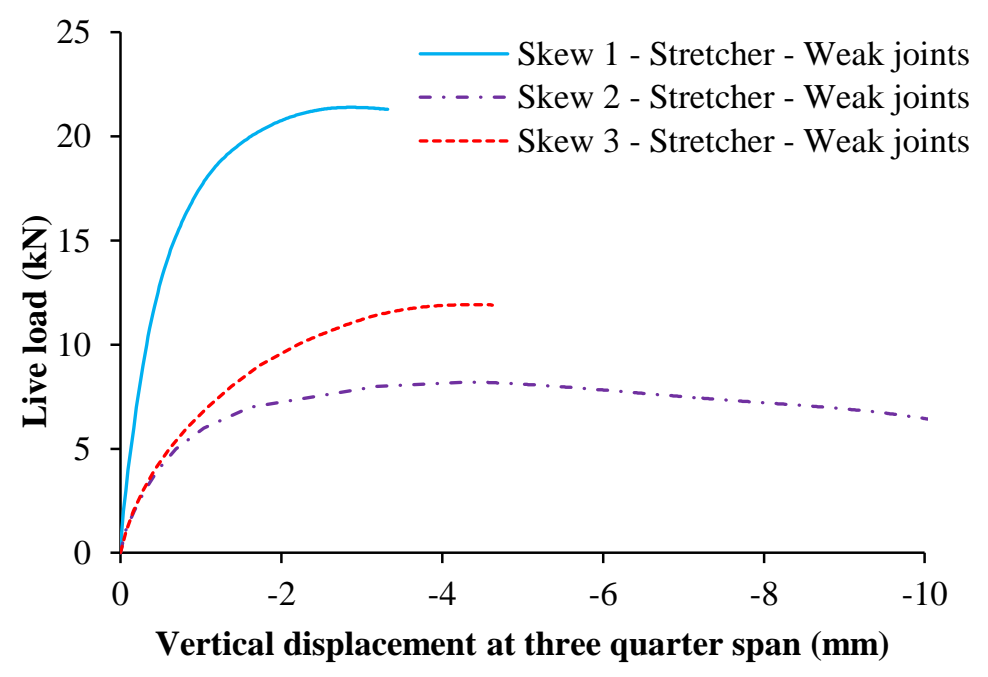

Figure 30. L-D curves for skew arches with weak joints 


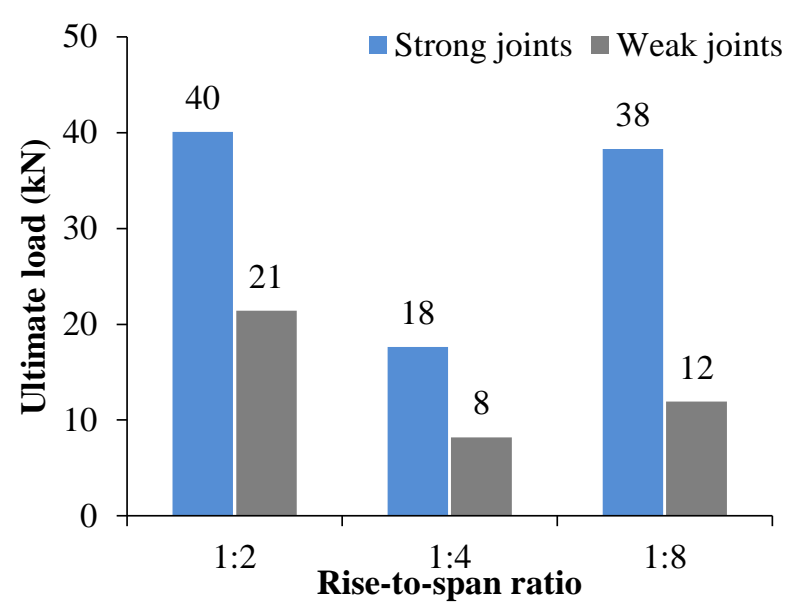

(a)

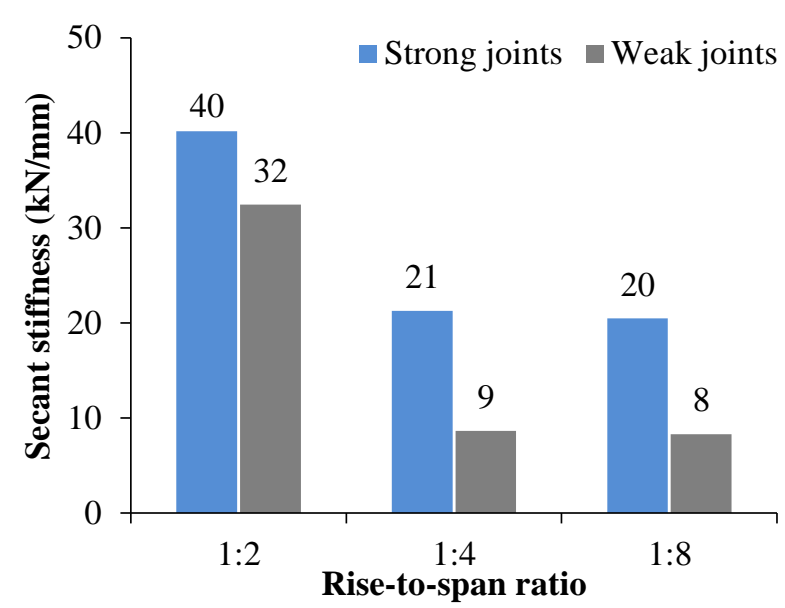

(b)

Figure 31. Influence of bond and defects on skew arches with different rise-to-span ratio on (a) ultimate load and (initial stiffness)

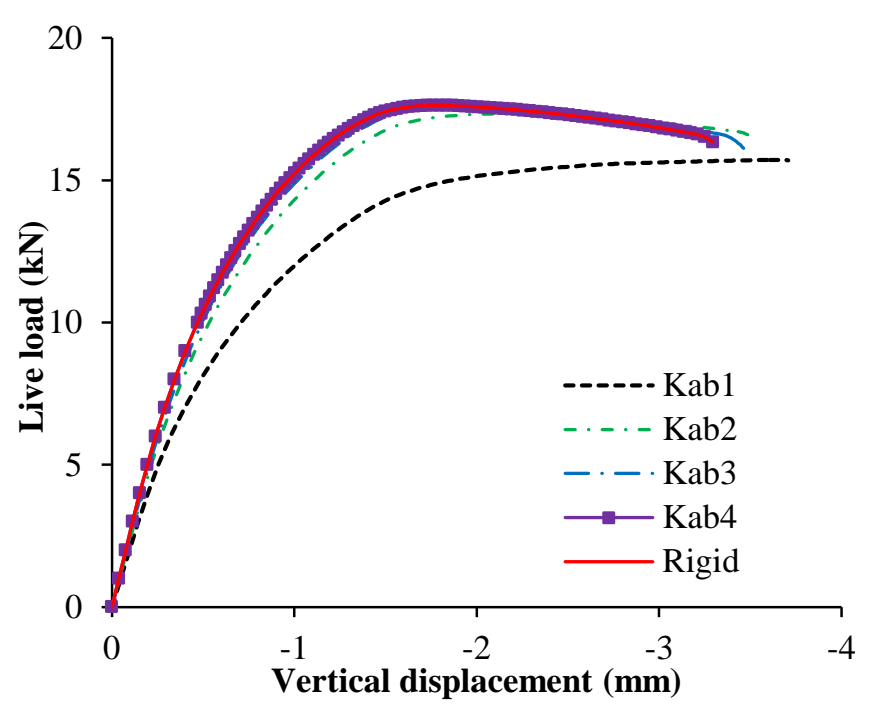

(a)
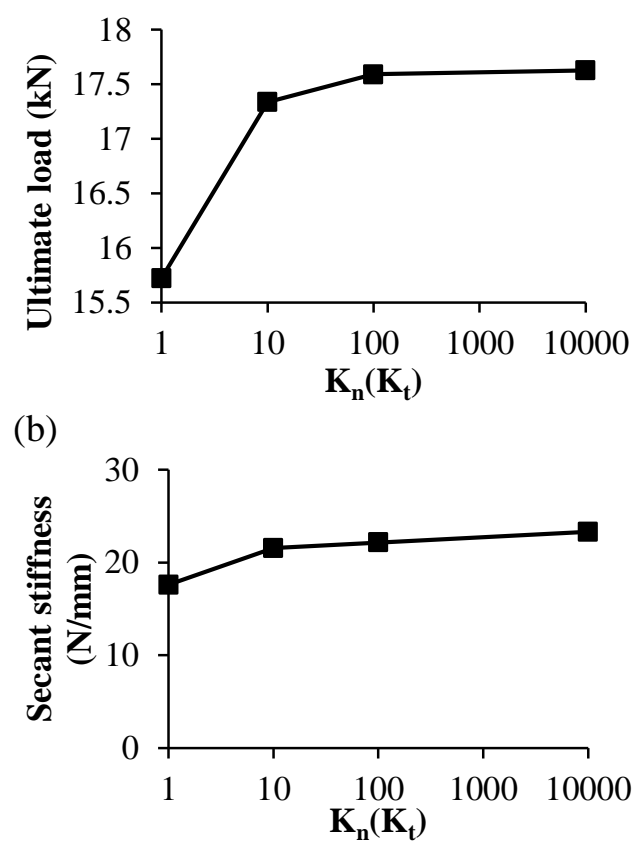

(c)

Figure 32. Influence of abutment stiffness on the load capacity of the skew arch 


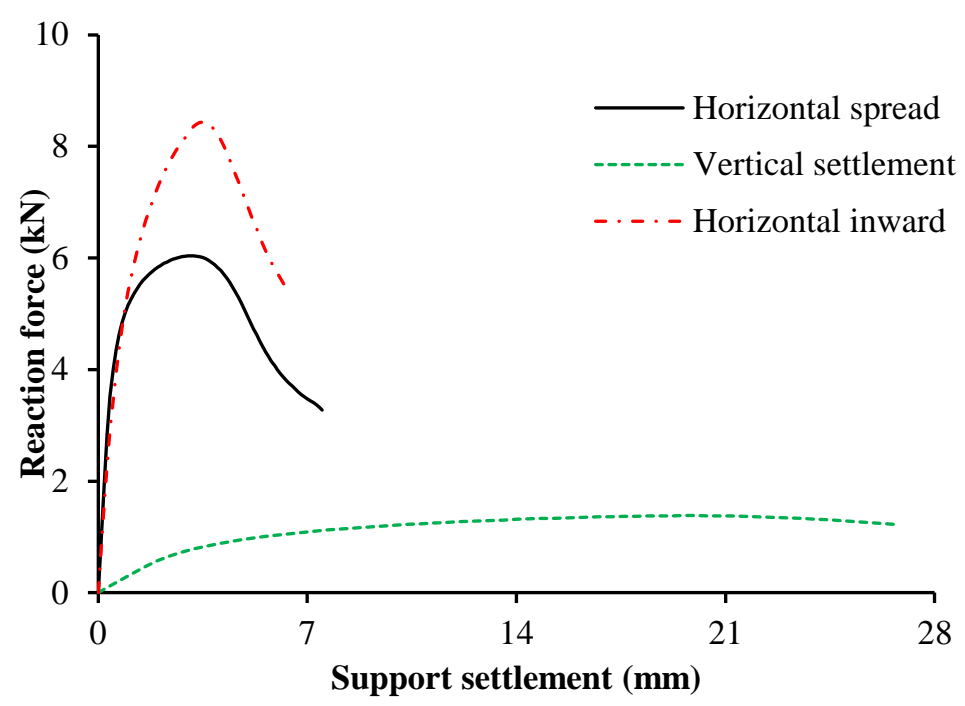

Figure 33. Reaction force-support displacement curves for arch Skew

\section{List of Tables}

Table 1: Geometry of square arches with different rise-to-span ratio

\begin{tabular}{|l|c|c|c|c|c|}
\hline Model & $\begin{array}{c}\text { Rise - H } \\
(\mathbf{m m})\end{array}$ & $\begin{array}{c}\text { Span - L } \\
(\mathbf{m m})\end{array}$ & No. of Rings & $\begin{array}{c}\text { Thickness } \\
(\mathbf{m m})\end{array}$ & Rise-to-span ratio \\
\hline Arch 1 & 1500 & 3000 & 2 & 215.0 & $1: 2$ \\
\hline Arch 2 & 750 & 3000 & 2 & 215.0 & $1: 4$ \\
\hline Arch 3 & 375 & 3000 & 2 & 215.0 & $1: 8$ \\
\hline Arch 4 & 300 & 3000 & 2 & 215.0 & $1: 10$ \\
\hline Arch 5 & 4000 & 8000 & 5 & 537.5 & $1: 2$ \\
\hline Arch 6 & 2000 & 8000 & 5 & 537.5 & $1: 4$ \\
\hline Arch 7 & 1000 & 8000 & 5 & 537.5 & $1: 8$ \\
\hline Arch 8 & 800 & 8000 & 5 & 537.5 & $1: 10$ \\
\hline
\end{tabular}

Table 2: Inelastic properties of nonlinear interface elements representing mortar joints in square arches

\begin{tabular}{|l|l|l|l|}
\cline { 2 - 4 } \multicolumn{1}{c|}{} & Surface $\boldsymbol{F}_{\mathbf{1}}$ & Surface $\boldsymbol{Q}_{\mathbf{1}}$ & Surfaces $\boldsymbol{F}_{\mathbf{2}}, \boldsymbol{Q}_{\mathbf{2}}$ \\
\hline & $C_{0}=0.07 \mathrm{~N} / \mathrm{mm}^{2}$ & $C_{0}=0.07 \mathrm{~N} / \mathrm{mm}^{2}$ & $D=24.50 \mathrm{~N} / \mathrm{mm}^{2}$ \\
$\begin{array}{l}\text { Mortar- } \\
\text { brick } \\
\text { interface }\end{array}$ & $\sigma_{\mathrm{t} 0}=0.05 \mathrm{~N} / \mathrm{mm}^{2}$ & $\sigma_{\mathrm{t} 0}=0.05 \mathrm{~N} / \mathrm{mm}^{2}$ & $\sigma_{\mathrm{c} 0}=24.50 \mathrm{~N} / \mathrm{mm}^{2}$ \\
& $\tan \phi_{0}=0.50$ & $\tan \psi_{0}=0.00$ & $\tan \theta_{0}=1.00$ \\
& $G_{f 1}=0.02 \mathrm{~N} / \mathrm{mm}$ & $G_{f 1}=0.02 \mathrm{~N} / \mathrm{mm}$ & $G_{\mathrm{c}}=5.00 \mathrm{~N} / \mathrm{mm}$ \\
& $G_{f 2}=0.125 \mathrm{~N} / \mathrm{mm}$ & $G_{f 2}=0.125 \mathrm{~N} / \mathrm{mm}$ & \\
\hline
\end{tabular}


Table 3: Elastic stiffness values for the interface elements at the arch springings

\begin{tabular}{|c|c|c|}
\hline Model & $\begin{array}{c}\text { Normal stiffness, } \boldsymbol{K}_{\mathbf{n}} \\
\left(\mathbf{N} / \mathbf{m m}^{\mathbf{3}}\right)\end{array}$ & $\begin{array}{c}\text { Tangent stiffness, } \boldsymbol{K}_{\mathbf{t}} \\
\left(\mathbf{N} / \mathbf{m m}^{\mathbf{3}}\right)\end{array}$ \\
\hline $\boldsymbol{K}_{\mathrm{ab} 1}$ & $1.00 \times 10^{0}$ & $1.00 \times 10^{0}$ \\
\hline $\boldsymbol{K}_{\mathrm{ab} 2}$ & $1.00 \times 10^{1}$ & $1.00 \times 10^{1}$ \\
\hline $\boldsymbol{K}_{\mathrm{ab} 3}$ & $1.00 \times 10^{2}$ & $1.00 \times 10^{2}$ \\
\hline $\boldsymbol{K}_{\mathrm{ab} 4}$ & $1.00 \times 10^{4}$ & $1.00 \times 10^{4}$ \\
\hline Rigid & - & - \\
\hline
\end{tabular}

Table 4: Geometry of the skew arches with different rise-to-span ratio

\begin{tabular}{|l|c|c|c|c|c|}
\hline Model & $\begin{array}{c}\text { Rise - } \boldsymbol{H} \\
(\mathbf{m m})\end{array}$ & $\begin{array}{c}\text { Direct span - } \boldsymbol{L}_{\mathbf{d}} \\
(\mathbf{m m})\end{array}$ & No. of Rings & $\begin{array}{c}\text { Thickness } \\
(\mathbf{m m})\end{array}$ & Rise-to-span ratio \\
\hline Skew 1 & 1500 & 3000 & 2 & 215 & $1: 2$ \\
\hline Skew 2 & 750 & 3000 & 2 & 215 & $1: 4$ \\
\hline Skew 3 & 375 & 3000 & 2 & 215 & $1: 8$ \\
\hline
\end{tabular}

Table 5: Inelastic properties of nonlinear interface elements employed for skew arches

\begin{tabular}{|l|l|l|l|}
\cline { 2 - 4 } \multicolumn{1}{c|}{} & Surface $\boldsymbol{F}_{\mathbf{1}}$ & Surface $\boldsymbol{Q}_{\mathbf{1}}$ & Surfaces $\boldsymbol{F}_{\mathbf{2}}, \boldsymbol{Q}_{\mathbf{2}}$ \\
\hline \multirow{4}{*}{$\begin{array}{l}\text { Mortar-brick } \\
\text { interface }\end{array}$} & $C_{0}=0.14 \mathrm{~N} / \mathrm{mm}^{2}$ & $C_{0}=0.14 \mathrm{~N} / \mathrm{mm}^{2}$ & $D=25.30 \mathrm{~N} / \mathrm{mm}^{2}$ \\
& $\sigma_{\mathrm{t} 0}=0.10 \mathrm{~N} / \mathrm{mm}^{2}$ & $\sigma_{\mathrm{t} 0}=0.10 \mathrm{~N} / \mathrm{mm}^{2}$ & $\sigma_{\mathrm{c} 0}=25.30 \mathrm{~N} / \mathrm{mm}^{2}$ \\
& $\tan \phi_{0}=0.60$ & $\tan \psi_{0}=0.00$ & $\tan \theta_{0}=1.00$ \\
& $G_{f 1}=0.12 \mathrm{~N} / \mathrm{mm}$ & $G_{f 1}=0.12 \mathrm{~N} / \mathrm{mm}$ & $G_{\mathrm{c}}=5.00 \mathrm{~N} / \mathrm{mm}$ \\
& $G_{f 2}=0.15 \mathrm{~N} / \mathrm{mm}$ & $G_{f 2}=0.15 \mathrm{~N} / \mathrm{mm}$ & \\
\hline
\end{tabular}

